\title{
Targeted Therapeutic Strategies in the Battle Against Pathogenic Bacteria
}

OPEN ACCESS

Edited by:

Vengadesh Letchumanan,

Monash University, Malaysia

Reviewed by:

Julio Plaza-Diaz,

Children's Hospital of Eastern Ontario

(CHEO), Canada

Adzzie Shazleen Azman,

Monash University Malaysia, Malaysia

*Correspondence:

Qingyan LV

lqy2018@yeah.net

Zhiqiang Wang

zqwang@yzu.edu.cn

Yuan Liu

liuyuan2018@yzu.edu.cn

Specialty section:

This article was submitted to

Experimental Pharmacology and Drug

Discovery,

a section of the journal

Frontiers in Pharmacology

Received: 27 February 2021

Accepted: 23 April 2021

Published: 12 May 2021

Citation:

Yang $B$, Fang $D, L v Q$, Wang $Z$ and

Liu Y (2021) Targeted Therapeutic

Strategies in the Battle Against

Pathogenic Bacteria.

Front. Pharmacol. 12:673239.

doi: 10.3389/fphar.2021.673239

\author{
Bingqing Yang ${ }^{1}$, Dan Fang ${ }^{1}$, Qingyan Lv $^{1,2,3 *}$, Zhiqiang Wang ${ }^{1,2,3 *}$ and Yuan Liu ${ }^{1,2,3,4 *}$ \\ ${ }^{1}$ College of Veterinary Medicine, Yangzhou University, Yangzhou, China, ${ }^{2}$ Joint International Research Laboratory of Agriculture \\ and Agri-Product Safety, The Ministry of Education of China, Yangzhou University, Yangzhou, China, '3iangsu Co-Innovation \\ Center for Prevention and Control of Important Animal Infectious Diseases and Zoonoses, Yangzhou University, Yangzhou, China, \\ ${ }^{4}$ Institute of Comparative Medicine, Yangzhou University, Yangzhou, China
}

The emergence and rapid spread of antibiotic resistance in pathogenic bacteria constitute a global threat for public health. Despite ongoing efforts to confront this crisis, the pace of finding new potent antimicrobials is far slower than the evolution of drug resistance. The abuse of broad-spectrum antibiotics not only accelerates the formation of resistance but also imposes a burden on the intestinal microbiota, which acts a critical role in human homeostasis. As such, innovative therapeutic strategies with precision are pressingly warranted and highly anticipated. Recently, target therapies have achieved some breakthroughs by the aid of modern technology. In this review, we provide an insightful illustration of current and future medical targeted strategies, including narrowspectrum agents, engineered probiotics, nanotechnology, phage therapy, and CRISPRCas9 technology. We discuss the recent advances and potential hurdles of these strategies. Meanwhile, the possibilities to mitigate the spread of resistance in these approaches are also mentioned. Altogether, a better understanding of the advantages, disadvantages, and mechanisms of action of these targeted therapies will be conducive to broadening our horizons and optimizing the existing antibacterial approaches.

Keywords: targeted therapeutic strategies, pathogenic bacteria, probiotics, phage, CRISPR-Cas9

\section{INTRODUCTION}

The past few centuries have witnessed the ceaseless battles between pathogenic bacteria and antibiotics. Although the proceeding of antibiotic discovery is never at a standstill, bacteria have numerous strategies to escape from antibiotic killing and even upgrade to the so-called superbug. Typical examples lie in the appearance of multidrug-resistant (MDR) bacteria, such as the notorious vancomycin-resistant enterococci (VRE) (Gonzales et al., 2001) and extended spectrum beta-lactamase (ESBL)-producing Enterobacteriaceae (Paterson et al., 2003). Besides, the globalization of resistance is without doubt making things worse, as is reflected in the dissemination and prevalence of New Delhi metallo-beta-lactamase-1 (NDM-1) from India to Pakistan, the United States, Canada, Japan, and the United Kingdom (Walsh et al., 2011). As the European Centre for Disease Prevention and Control (ECDC) revealed, there were approximately 25,000 people dying from infections caused by MDR bacteria every year just in Europe (Carlet and Mainardi, 2012). A recent report published by the United Kingdom government also predicted that the global death toll would increase to 10 million by 2050 if new antimicrobial strategies were not discovered (O'Neill, 2016). Evidently, now is the time people are stepping into the "post-antibiotic" era, in which resistance crisis appears, and many antimicrobials are no longer effective. 
The rapid emergence and evolution of antibiotic resistance can be attributed to many reasons, such as inappropriate treatment regimen and supplement in feed as animal growth promoter, among which the abuse of broad-spectrum antimicrobials plays a dominant role. In particular, owing to the lack of rapid diagnosis of pathogens, broad-spectrum antibiotics are empirically employed in nosocomial infections as countermeasures. However, their indiscriminate killing modes and the accompanying selective pressure really promote the emergence of antibiotic resistance. To be specific, antibiotic treatment kills all sensitive bacteria, while a part of them gradually acquire resistant mutations and survive. Additionally, broad-spectrum antimicrobials impose detrimental effects on the structure and diversity of intestinal microbiota. However, it is widely acknowledged that a balanced intestinal microbiota plays an important role in human health. For one thing, it helps to absorb nutrition and maintain the regular intestinal motility. For another thing, gut microbiota can inhibit the invasion of pathogenic bacteria or opportunistic bacteria through spaceoccupying protection and the production of substances such as bacteriocin, organic acid, and hydrogen peroxide. Without the restriction of normal microbiota, the overgrowth of drugresistant bacteria will inevitably lead to serious dysbacteriosis like pseudomembranous colitis (PMC), which is often known as the so-called off-target effects (Blaser, 2016). Sometimes, the side effects of longtime antibiotic intake like hyperspasmia, coma, tinnitus, nausea, and renal insufficiency also bring about much trouble to the patients.

Given all of the above, the exploitation and application of antimicrobials are always necessary to combat against the increasingly serious resistance crisis. Under this premise, hunting for more precise and targeted antimicrobial strategies capable of protecting our normal microbiota seems more significant. At present, with the swift development and innovation of modern science and technology, a great number of inspirations and assumptions have been put forward and realized in precise sterilization. Herein, we discuss recent advances and the prospects of targeted therapeutic strategies in the fight against pathogenic bacteria, including narrowspectrum agents, engineered probiotics, nanotechnology, phage therapy, and CRISPR-Cas9 technology.

\section{NARROW-SPECTRUM ANTIMICROBIAL AGENTS}

The broad-spectrum antimicrobial agents are empirically employed in clinical settings because the long time to perform bacteria isolation and identification may lead to treatment delay and condition deterioration. Also, broad-spectrum agents possess the ability to kill an extensive scope of bacteria, which is suitable for clinically common mixed infections. However, the indiscriminate killing mode of broad-spectrum agents results in the death of all bacteria, thus disturbing the microbiota balance and even inducing the superinfection. For instance, 2to 7-year-old Finnish children treated with macrolide showed a long-lasting shift in microbiota composition and metabolism, including increase abundance of Bacteroidetes and Proteobacteria, decrease in bile-salt hydrolase, and increase in macrolide resistance (Korpela et al., 2016). On the contrary, more pointed narrow-spectrum antimicrobial agents, including narrow-spectrum antibiotics, antibacterial peptides (AMPs), and lysins, show the possibility to cope with this dilemma and achieve targeted therapy.

\section{Narrow-Spectrum Antibiotics}

Since the discovery of penicillin, a series of antibiotics have been exploited from soil, marine, insect, human, and plant. They perform killing or inhibiting functions based on different targets and different bacterial phases. As the most dominant traditional antimicrobial agent, antibiotics never let us down until nowadays although there is a slowdown recently in finding new sources. Among these rich resources, narrow-spectrum antibiotics outstand due to their precise modes of action without additional effects (Table 1).

In fact, some of them are still based on previously reported targets such as cell wall synthesis, membrane permeability, protein synthesis, and DNA transcription. For example, fidaxomicin, derived from Dactylosporangium aurantiacum, possessed distinctive bactericidal activity against Clostridioides difficile but minimal activity against the original gut microbiota (Sears et al., 2013). As an RNA polymerase inhibitor, it was different from rifampicin as it inhibited RNA polymerase in the early stage of transcription, even prior to initiation of mRNA synthesis. Thuricin Z, a novel sactibiotic from Bacillus thuringiensis, was also reported to be capable of causing membrane permeabilization of Bacillus cereus with specificity (Mo et al., 2019). Another exciting incident was the discovery of soil-derived teixobactin, which was only active against Grampositive bacteria (Ling et al., 2015). It could inhibit the synthesis of cell wall by binding to a highly conserved motif of lipid II (precursor of peptidoglycan) and lipid III (precursor of teichoic acid) without detectable resistance.

Additionally, the appearance of new targets or new mechanisms seems more attractive. For example, an antibiotic termed ridinilazole was found efficient in the treatment of $C$. difficile infections through enhancing the preservation of microbiota-dependent bile acid metabolome without interfering with the commensal microbiota (Qian et al., 2020). Moreover, antibiotics with killing modes based on energy metabolism inhibition show a novel pipeline for drug development. A thiochromenone antibiotic derived from the Pseudomonas quinolone signal (PQS) exhibited highly potent antibiotic activity against Moraxella catarrhalis likely by inhibiting a target in the primary energy metabolism (Szamosvári et al., 2019). Consistently, cellular ATP concentrations in $M$. catarrhalis dropped significantly after exposure to this compound. However, the specific targets of this thiochromenone antibiotic are still unclear. Similarly, lugdunin was reported to be related to the swift breakdown of bacterial energy resources as it ceased the incorporation of radioactive precursors of DNA, RNA, protein, and cell wall under low concentrations nearly at the meantime (Zipperer et al., 2016). It is noteworthy that lugdunin was capable of 
TABLE 1 | Sources, spectrums, and modes of action of representative narrow-spectrum antibiotics.

\begin{tabular}{|c|c|c|c|c|}
\hline Antibiotics & Sources & $\begin{array}{l}\text { Antibacterial } \\
\text { spectrums }\end{array}$ & Modes of action & References \\
\hline Fidaxomicin & Dactylosporangium aurantiacum & C. difficile & Inhibits RNA polymerase & Sears et al. (2013) \\
\hline Ridinilazole & Unknown & C. difficile & $\begin{array}{l}\text { Enhances the preservation of microbiota- } \\
\text { dependent bile acids }\end{array}$ & Qian et al. (2020) \\
\hline Teixobactin & Uncultured organisms & Gram-positive bacteria & Inhibit the synthesis of cell wall & Ling et al. (2015) \\
\hline $\begin{array}{l}\text { A thiochromenone } \\
\text { antibiotic }\end{array}$ & Pseudomonas quinolone signal & Moraxella catarrhalis & $\begin{array}{l}\text { Inhibits a target in the primary energy } \\
\text { metabolism }\end{array}$ & $\begin{array}{l}\text { Szamosvári et al. } \\
\text { (2019) }\end{array}$ \\
\hline Thuricin Z & Bacillus thuringiensis & B. cereus & Causes membrane permeabilization & Mo et al. (2019) \\
\hline Lysocin E & Soil bacteria & $\begin{array}{l}\text { Bacteria with } \\
\text { menaquinone }\end{array}$ & Loss of membrane potential & $\begin{array}{l}\text { Hamamoto et al. } \\
(2015)\end{array}$ \\
\hline Lugdunin & Human-associated bacteria & Gram-positive bacteria & Breakdown of bacterial energy resources & $\begin{array}{l}\text { Zipperer et al. } \\
(2016)\end{array}$ \\
\hline $\begin{array}{l}\text { Corbomycin and } \\
\text { complestatin }\end{array}$ & Actinomycetes & Gram-positive bacteria & Inhibits peptidoglycan remodeling & Culp et al. (2020) \\
\hline Darobactin & $\begin{array}{l}\text { Photorhabdus symbionts of entomopathogenic } \\
\text { nematode microbiomes }\end{array}$ & Gram-negative bacteria & $\begin{array}{l}\text { Disrupts the formation of a functional } \\
\text { outer membrane }\end{array}$ & Imai et al. (2019) \\
\hline G0775 & Arylomycins & Gram-negative bacteria & Inhibits bacterial type I signal peptidase & Smith et al. (2018) \\
\hline Ilamycins E1/E2 & Streptomyces atratus SCSIO ZH16 & M. tuberculosis & Unknown & Ma et al. (2017) \\
\hline Novel griselimycins & Streptomyces & M. tuberculosis & $\begin{array}{l}\text { Inhibits the DNA polymerase sliding clamp } \\
\text { dnan }\end{array}$ & Kling et al. (2015) \\
\hline Linezolid & Synthetic antibiotic & Gram-positive bacteria & Inhibits bacterial protein synthesis & $\begin{array}{l}\text { Hashemian et al. } \\
\text { (2018) }\end{array}$ \\
\hline Daptomycin & S. reseosporus & Gram-positive bacteria & Disrupts cell membrane & Heidary et al. (2018) \\
\hline Microcin B17 & Bacteria with pMccB17 & Gammaproteobacteria & Inhibits DNA replication & $\begin{array}{l}\text { Collin and Maxwell } \\
\text { (2019) }\end{array}$ \\
\hline Plantazolicin & $\begin{array}{l}\text { Bacillus methylotrophicus FZB42 and Bacillus } \\
\text { pumilus }\end{array}$ & B. anthracis & Disrupts cell membrane & $\begin{array}{l}\text { Molohon et al. } \\
(2016)\end{array}$ \\
\hline NVB302 & Deoxyactagardine B & C. difficile & Inhibits cell wall biosynthesis & $\begin{array}{l}\text { Petrosillo et al. } \\
\text { (2018) }\end{array}$ \\
\hline
\end{tabular}

coping with a series of Gram-positive bacteria, especially the notorious methicillin-resistant $S$. aureus (MRSA) and the VRE isolates.

Together, these precise antibiotics harbor few and critical sites of action that closely take part in bacterial survival and reproduction. They can be more suitable, more efficient, and would not induce the subsequent severe infections. One of the principles of antibiotic use is the prioritization of narrowspectrum antibiotic, especially when we have figured out the specific pathogenic bacteria. It is good news for clinical treatment but indeed places a higher expectation on rapid diagnosis.

\section{Narrow-Spectrum AMPs}

Antimicrobial peptides (AMPs), also called host-defense peptides (HDPs), are important components of the innate immune system (Lazzaro et al., 2020). As their modes of action primarily depend on the mechanism involving electrostatic interactions between their cationic domains and negatively charged bacterial cell surface, AMPs have a lower likelihood to induce host toxicity because eukaryotic cell membrane is electrically neutral (Jenssen et al., 2006). In this regard, AMPs are not prone to induce drug resistance, thus showing broad prospects to perform as ideal antibiotic alternatives in this resistance era (Liu et al., 2021). More importantly, AMPs with targeted activity turn out to be good choices for precise killing. For instance, the AMP thanatin from Podisus maculiventris was found to reverse carbapenem resistance in NDM-1-producing bacteria by dual mechanisms
(Ma et al., 2019), that is, disrupting the outer membrane by competitively displacing divalent cations and inhibiting the enzymatic activity of NDM-1 by displacing zinc ions from the active site. ZY4, a cyclic peptide, not only induced membrane permeabilization in bacteria with low frequency of resistance but also showed supreme potency in coping with persister cells (Mwangi et al., 2019). It had been confirmed to be able to combat with multidrug-resistant $P$. aeruginosa and $A$. baumannii infections potently than Bacillus subtilis and S. aureus.

Except membrane disruption, AMPs also play a part in several intracellular processes. In a previous work, it was reported that sublethal concentrations of P-Der from pleurocidin or frog dermaseptin could inhibit macromolecular synthesis in Escherichia coli (Patrzykat et al., 2002). Additionally, targets relevant to the formation of structural components are also worthy to be noted. For instance, a non-ribosomal lipopeptide tridecaptin A1 (TriA1) produced by Bacillus and Paenibacillus species exerted antibacterial activity against Gram-negative bacteria by binding to lipid II on the inner membrane and disrupting the proton motive force (Cochrane et al., 2016). Besides, strategies based on database-filtering technology provided us inspiration to generate ideal, short, specific, and effective AMPs. For instance, the potential peptides F1 and F4 from the antimicrobial peptide database (APD) with an $\alpha$-helical symmetrical structure displayed short, safe, and stable activity against Gram-negative pathogens such as E. coli, S. pullorum, and P. aeruginosa (Chou et al., 2019). However, their activities against 
Gram-positive bacteria were very poor as reflected in the high MIC values in $S$. epidermidis and $P$. aeruginosa.

Until recently, although peptide antibiotics such as polymyxin $\mathrm{B}$, colistin, and daptomycin have been put into clinical use for decades, doubts and criticisms constantly exist due to their incomplete success with dose-dependent toxicity and short half-life in vivo. So, after sophisticated designing and screening, AMPs with activities still need to undergo tests in terms of protease stability and cytoxicity. In this case, structural modification such as lipophilic fatty acid chain removal (Liu et al., 2017) and strategies providing protease resistance such as amino acid type replacement (Braunstein et al., 2004) deserve serious consideration.

\section{Narrow-Spectrum Lysins}

At the end of the lytic cycle of bacteriophages, lysins will be released and accumulated in the cytoplasm (Fischetti, 2008). The nature of lysin is enzyme, which is composed of two parts: the catalytic domain in the $\mathrm{N}$-terminal region and the binding domain in the $C$-terminal region. The former exhibits catalytic activity, and the latter has specificity for molecules existing in the host cell wall. Considering this mode of action, we may conclude their excellent activities against Gram-positive bacteria with cell wall and the inefficiency toward Gram-negative bacteria possessing an impermeable outer membrane. However, based on comprehensive understanding, lysins are indeed potent targeted antimicrobial agents owing to their high specificity, low frequency of resistance, and rich sources (Sharma U. et al., 2018). First and foremost, the values of lysins in infection control, especially in aquaculture and stock farming, have been partly acknowledged. One typical example is the lysin PlyC produced by phage $\mathrm{C}$, which had distinctive and exclusive therapeutic activity against Streptococcus sp., whose swift propagation has confused many horse owners (McGowan et al., 2012). Likewise, Cpl-1 and Pal, lysins isolated from active bacteriophages against Streptococcus pneumoniae, targeted the same host but exhibited different catalytic activities (Jado et al., 2003). It is noteworthy that this synergy mechanism indeed reduced the emergence of resistance to lysins. Additionally, working in coordination with oxacillina, the chimeric lysin Clys, synthesized by the fusion of the $N$-terminal domain of phage Twort lysin, and the $C$-terminal domain of the phage phiNM3 lysin, exhibited good protection against MRSA in in vivo models (Daniel et al., 2010). It is without doubt an imperative work as MRSA is responsible for various skin and soft-tissue infections and symptoms associated with dairy cow mastitis. Another lysin with the same target is CF-301, which was specialized in disrupting $S$. aureus biofilms (Schuch et al., 2017).

The flooding of lysins is also good news for all kinds of nosocomial infections. PlyE146, a novel lysin derived from phage genome-based screening, exhibited supreme bactericidal activity and promising therapeutic efficacy against E. coli, $P$. aeruginosa, and A. baumannii (Larpin et al., 2018). It is no exaggeration to say that these pathogens really suffer numerous patients racked with septicemia, peritonitis, and urinary-tract infections. However, in other tested strains such as K. pneumoniae, S. enterica, S. aureus, and S. mitis, no antibacterial activity was observed.

Food industry also benefits a lot during these endeavors. Ply3626 was reported to display potent activity against Clostridium perfrigens, a common pathogen closely related to food poisoning (Zimmer et al., 2002). And as for Ply511, when it was cloned in and secreted by L. lactis, it could inhibit the pathogenic Listeria monocytogenes during the production of dairy starter cultures, thus showing bio-preservation properties (Gaeng et al., 2000).

Although lysins released by phages are somewhat ignored or underestimated, they still have a place in antibacterial treatment. As enzyme preparations, they are relatively safe to the host and easy to control. Also, through genetic engineering technology, catalytic domains and binding domains of different lysins can be connected to form chimeric lysins with high bactericidal activities (Kim et al., 2019). Considering its rich resources, phage lysin is regarded as an ideal agent with potential and distinction in preventing and controlling bacterial infections.

\section{ENGINEERED PROBIOTICS}

Due to extensive use of antibiotics, many infectious diseases have been cured, but a series of side effects spring up, such as the increasing sensitivity. In this case, drugs with auxiliary and complementary effects for antibiotics are urgently warranted. Probiotic was first defined by Lilly and Stillwell to describe substances produced by protozoa to stimulate the growth of another organism (Lilly and Stillwell, 1965). Long before, their existences in fermented milk were regarded as the secret of good health and longevity in Bulgaria. Thereafter, their efficacies in inhibiting the growth of several pathogenic bacteria and preventing antibiotic-associated diarrhea were gradually found. Hence, they were described as live nonpathogenic bacterial species administered to provide beneficial effects to host through regulating microbial balance, particularly in the gastrointestinal tract (Williams, 2010). Within these decades, advancements in synthetic biology also render it possible to achieve targeted antimicrobial therapy through designing sophisticated engineered probiotics with desired characteristics and functions. Herein, we will discuss the reconstruction and utilization of probiotics in targeted therapy from two main angles.

\section{Producing or Transporting Specific Antimicrobial Molecules}

On the one hand, engineered probiotics can serve as optimal vectors to produce or transport antibacterial molecules targeting specific pathogens. The combination of probiotics and targeted peptides is one of good choices. One example is L. lactis IL1403, a reconstructed $L$. lactis that expressed antimicrobial peptides aiming at Gram-negative pathogenic bacteria (Volzing et al., 2013). Herein, synthetic peptides A3APO and alyteserin were sorted out due to their supreme performances among numerous candidates in strong activity against $E$. coli and Salmonella while lower activity against L. lactis. Another example lies in E. coli 


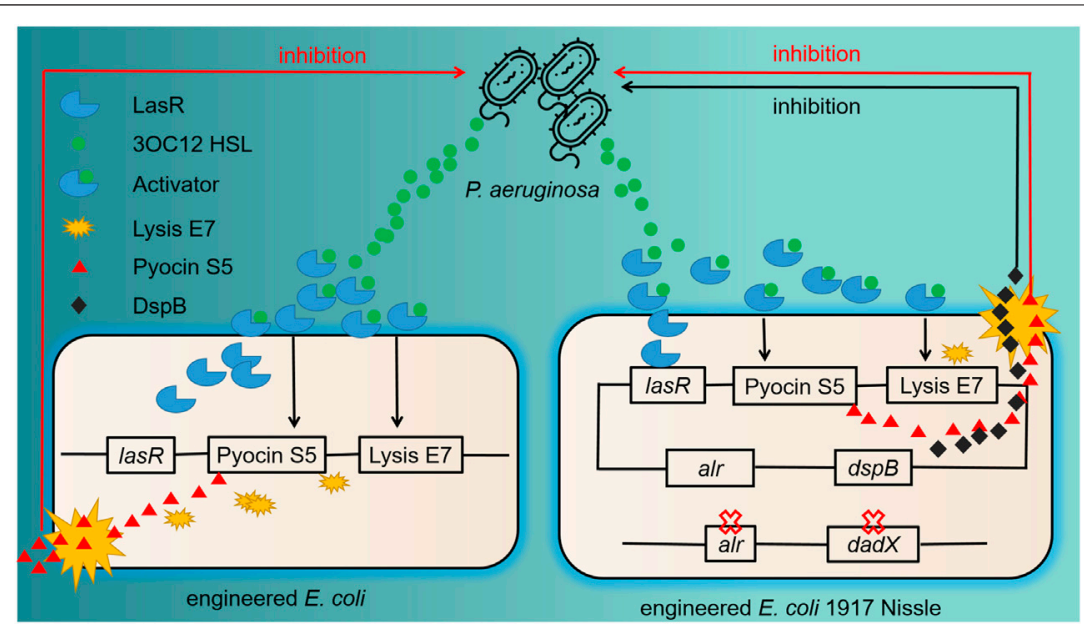

FIGURE 1 | Previous and further improved antimicrobial engineered probiotics through quorum sensing. The left part shows the schematic of the "sense-and-kill" system. 30C12HSL, the quorum-sensing molecule released by $P$. aeruginosa, binds with LasR to form LasR-3OC12HSL complex. This complex thereafter activates the production of E7 lysis protein and S5 pyocin. When the accumulation of E7 protein is enough to lead to the cell lysis, Pyocin S5 is released into the exogenous environment and kills $P$. aeruginosa. The right part shows the improvement of this system. The chromosomal deletion of alr and dadX genes in E. coli Nissle promotes the retention of plasmid carrying alr gene. An evident difference of the killing part is the addition of $d s p B$, which encodes an anti-biofilm enzyme with enhanced inhibition efficacy.

Nissle 1917, which was designed to express and secrete three antimicrobial peptides: Enterocin A, Enterocin B from $E$. faecalis, and Hiracin JM79 from E. hirae. They all processed distinctive activity against both E. faecium and E. faecalis, the chief culprits to blame for VRE infections (Geldart et al., 2018). In addition, probiotics producing functional fatty acids are also promising. For instance, Peng et al. (2018) increased the production of conjugated linoleic acids (CLAs) by overexpressing the myosin cross-reactive antigen gene ( $\mathrm{mcra}$ ) in Lactobacillus casei (LC) to specifically inhibit Salmonella enterica serovar Typhimurium (ST) and enterohaemorrhagic Escherichia coli (EHEC) in gut intestinal infections. Moreover, enzymes with degradation activity can also be employed. In a recent research, Chappell and Nair (2020) rendered two lactobacilli the ability to secrete enzymes degrading $P$. aeruginosa biofilms, and the best-designed engineered lactic acid bacteria producing PA14-derived enzyme $\left(\mathrm{PelA}_{\mathrm{h}}\right)$ exhibited a high degrading rate up to $85 \%$.

\section{Bacteria-Specific Sense-and-Kill System}

On the other hand, engineered probiotics are designed to sense the specific metabolites produced by pathogens and make responses. The involvement of probiotics indeed makes sense as it is different from exogenously inserted plasmids which inevitably bring about additional burden to the host. The existence of probiotics makes up for the defects of their commensal bacteria or provides some advantages, which explains hosts' allowance of their consistent existences. However, this mechanism somewhat has specificity as it relies on the quorum-sensing phenomenon or exclusive properties of several pathogens to utilize or secrete some compounds in competitive environment. In this section, we select some typical pathogens to describe at length, owing to their non- negligible perniciousness, that is, $P$. aeruginosa, Salmonella, and $V$. cholerae.

\section{$P$. aeruginosa Infections}

$P$. aeruginosa, a Gram-negative pathogen, can cause severe infections as it harbors natural resistance feature, biofilmforming abilities, and effective efflux systems (Chang et al., 2005). For combating $P$. aeruginosa infections, Saeidi et al. designed engineered E. coli with "sense-and-kill" system dependent on quorum sensing (Figure 1). In this system, the production of LasR was activated by $P$. aeruginosa quorumsensing molecule $\mathrm{N}$-acyl-homoserine lactone (AHL), which therefore opened up the expression of E7 lysis protein and pyocin S5. Once the E7 protein reached the threshold concentration of chassis lysis, the accumulated S5 was then released into the exogenous environment and killed $P$. aeruginosa efficiently (Saeidi et al., 2011). Thereafter, this system was optimized in E. coli Nissle 1917 with the addition of dispersin B (DspB), a new anti-biofilm enzyme produced by Actinobacillus actinomycetemcomitans with glycosyl hydrolase activity. Evaluation of the engineered probiotic strain in a $C$. elegans infection model and a mouse infection model showed good treatment results (Hwang et al., 2017).

\section{Salmonella Infections}

As a common bacterium of intestinal infection, Salmonella poses a threat to the health of human and animals such as livestock, rodents, and poultry (Mastroeni and Sheppard, 2004). Previous research showed that microcin $\mathrm{H} 47$ (MccH47), a chromosomeencoded peptide with high molecular mass from E. coli strain H47, inhibited the growth of Salmonella in vitro potently (Laviña et al., 1990). Meanwhile, the gene products of $t$ tr operon (ttrRSBCA) enabled Salmonella species to utilize tetrathionate 


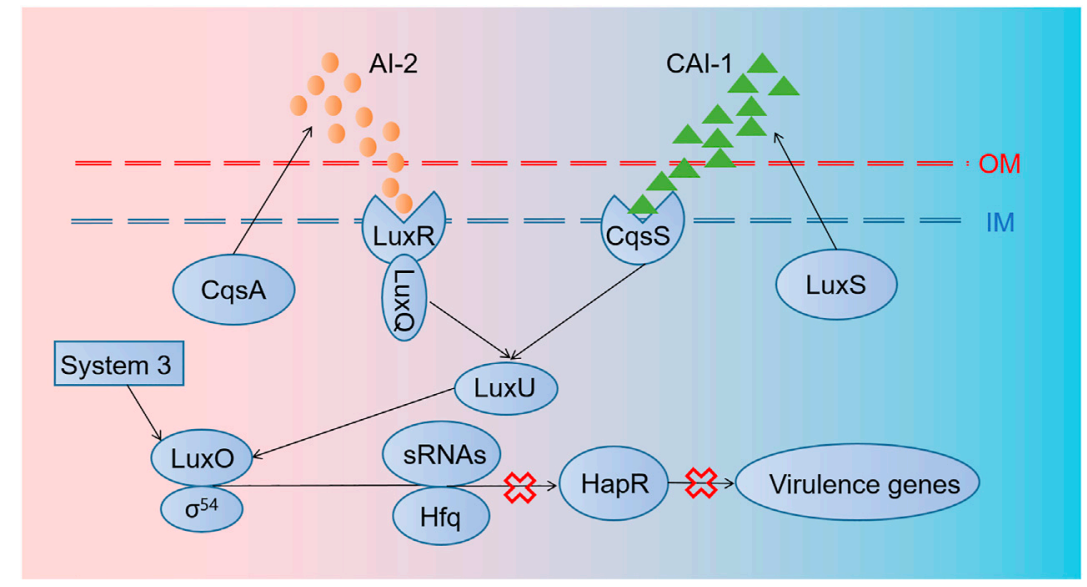

FIGURE 2 | Regulation mechanisms of quorum sensing in $\mathrm{V}$. cholerae. The parallel QS system of $\mathrm{V}$. cholerae possesses Al-2/LuxPQ and CAI-1/CqsS systems, as well as an unidentified third circuit that acts through LuxO. cqsA and luxS genes encode proteins producing Al-2 and CAl-1. Thereafter, Al-2 and CAl-1 are detected and captured by LuxRQ complex and CqsS, respectively, leading to the activation of LuxU and LuxO later. Then, with the aid of $\sigma^{54}$, sRNAs and their chaperones Hfq are transformed into sRNAs-Hfq complex, which inhibits the transcription of HapR mRNAs, thus blocking the forming of HapR, a transcription factor relevant to the expression of some virulence genes.

as an electron acceptor for respiration and outcompete other bacteria with a growth advantage. Tetrathionate is usually generated as the reaction of luminal thiosulfate and reactive oxygen species produced during gut inflammation (Winter et al., 2010). Therefore, Palmer et al. (2018) successfully reconstructed E. coli strain Nissle 1917 with a plasmid-based $\mathrm{MccH} 47$ induction system and tetrathionate sensing system to cope with Salmonella infections.

\section{V. cholerae Infections}

$V$. cholerae causes millions of deaths from cholera per year as it induces severe watery diarrhea by colonizing in the small intestine and producing toxins (Ali et al., 2015). The parallel QS system of $V$. cholerae possesses AI-2/LuxPQ and CAI-1/CqsS systems as well as an unidentified third circuit that acts through LuxO [Figure 2; Miller et al. (2002)]. They work together to coordinate gene expression when $V$. cholerae populations reach higher concentrations. In order to fight against $V$. cholerae, Duan and March (2010) employed an engineered commensal bacteria E. coli Nissle 1917 expressing AI-2 and CAI-1 simultaneously, which could disturb bacterial communication to inhibit $V$. cholerae virulence. Based on the same mechanism, Mao et al. (2018) designed a cholera-sensing and reporting system by engineered $L$. lactis through developing a receptor in $L$. lactis to detect CAI-1 from V. cholerae (Mao et al., 2018). Then, L. lactis could sharply reduce intestinal $V$. cholerae load and get an improved survival rate in the infected infant mice model by producing lactic acid. Another strategy was to compete with intestinal receptor binding with cholera toxins through designing a recombinant bacterium expressing glycosyltransferase genes, which terminated the production of a chimeric lipopolysaccharide (Focareta et al., 2006).

Hopefully, except bacteria from the genera Lactobacillus and nonpathogenic strains of $E$. coli as we discussed above, the yeast Saccharomyces boulardii, Bacillus spp, and bacteria of
Bifidobacterium can also be exploited, serving as excellent candidates (Kotzampassi and Giamarellos-Bourboulis, 2012). The mechanism of probiotic can be concluded as a first recovery of microbiota balance and the following outgrowth of probiotics to cope with pathogenic bacteria. Usually, their modes of action are direct, while there are also some interactions between bacteria and host immune defenses (Isolauri et al., 2002).

\section{NANOMATERIAL-BASED TARGETED THERAPY}

Despite the emergence of a good many antimicrobial agents, the mortality of bacterial infections, especially in nosocomial settings, keeps high constantly. As we know, traditional "naked drug" delivery is the process of delivering therapeutic molecules to the targeted cells or tissues. It has relatively low efficacy as it goes through the experience of administration, distribution, absorption, and elimination. During these processes, effective drug only accounts for a little part of the total as restrictions in vivo and renal clearance. Hence, nanoparticle-aided systems (nanotechnology) outstand with high transport efficacy, realizing prolonged and sustained release of drugs and their maximized plasma half-life. In this section, concluding from various specialized designs, we briefly illustrate the interactive modes of nanoparticles with antibody, peptide, membrane, and other materials in targeted therapy against pathogens (Figure 3).

\section{Antibody-Based Targeted Nanoparticles}

Antibody is one kind of immunoglobulin that can specifically bind with antigen, harboring abilities such as neutralizing toxins, producing membrane attack complex, and mediating type I hypersensitivity. Besides these, antibodies can be ideal antimicrobial agents by means of virulence factor neutralization, enhancement of opsonophagocytic uptake and 


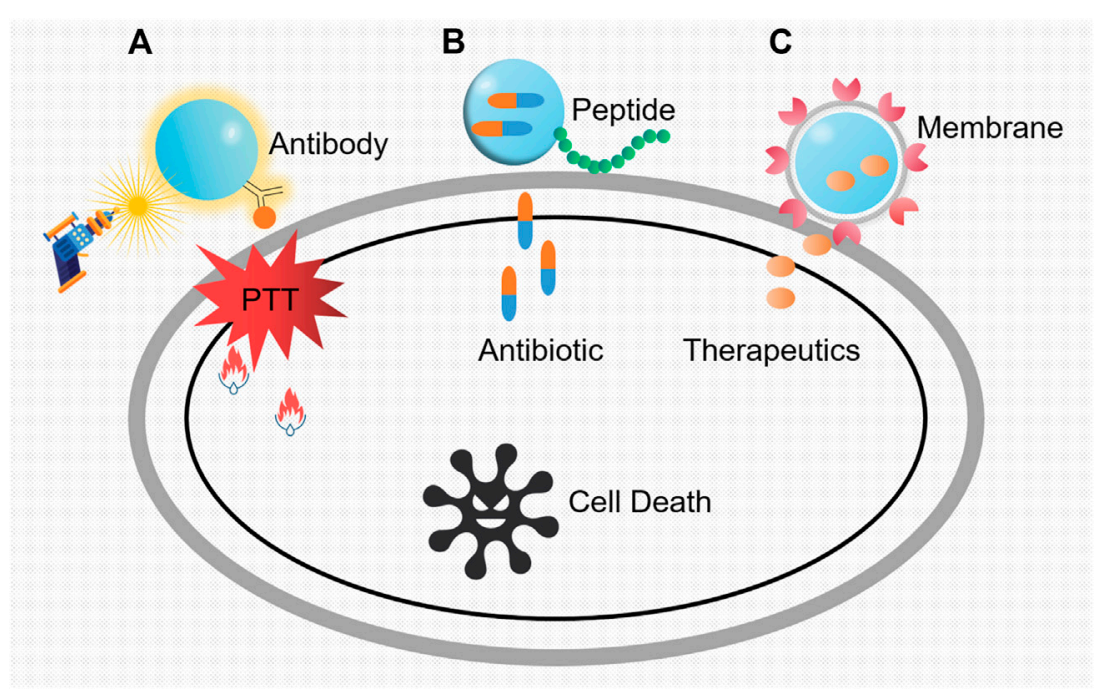

FIGURE 3 | Three main modes of nanoparticles as potent vehicles to target pathogens. (A) Killing mechanisms of nanoparticles loaded with antibody specific to the pathogenic bacteria. The constant exposure of laser irradiation was transformed into heat, which leads to the regional cell damage and the inevitable cell death. PTT refers to photothermal therapy. (B) Antibiotic-loaded nanoparticles with targeted peptides. After the identification of the specific bacterial region, the shell breaks and the inside antibiotic releases. (C) The action modes of nanoparticles coated with vesicles from platelet membrane. Owing to the pretreatment with specific bacteria, markers on vesicle membranes will conduct recognition, and the target bacteria will be killed by the subsequent release of the therapeutics.

killing (OPK), and complement-mediated bacterial lysis (Nagy et al., 2017). Through the specific combination of antigens and antibodies, metal nanoparticles with antibodies can target pathogens and perform bactericidal activities with intrinsic characteristic such as photothermal effect. For example, Millenbaugh et al. (2015) conjugated gold nanoparticles to antibodies specific to $S$. aureus peptidoglycan (Figure $3 \mathbf{A}$ ). Then, this complex was co-incubated with suspensions of MRSA and methicillin-sensitive $S$. aureus (MSSA) before laser irradiation, which led to significantly decreased bacteria viability and population. Also, Shokri et al. (2015) successfully combined an anti-protein A antibody with polystyrene sulfonate (PSS)coated gold nanorods (GNRs) to target and kill MRSA through photothermal therapy. Likewise, as for S. typhimurium in food samples, nanoparticles with similar designs are also reported frequently (Jeyaraj Pandian et al., 2017). In addition to photothermal sterilization, other enzyme-nanoparticle (NP) conjugates with lysostaphin were proved to be effective (Satishkumar and Vertegel, 2011).

Although antibody just plays a simple role in recognition and binding, it really shrinks the damage range of nanoparticles so as to avoid unnecessary hurt. Nowadays, as monoclonal antibodies harbor higher specificity, affinity, purity, and homogeneity, this combination will show extraordinary prospects in future diagnosis and treatment.

\section{Peptide-Based Targeted Nanoparticles}

Bacteria-targeting peptides can be alternatives to design potent nanoparticles in precise killing. As reported, Hussain et al. (2018) connected vancomycin-loaded nanoparticles with the cyclic 9amino-acid peptide CARGGLKSC (CARG) which could specifically bind to $S$. aureus, realizing more effective suppression of staphylococcal infections in vivo than untargeted treatment (Figure 3B). Moreover, magnetic nanoparticles (MNPs) could also serve as affinity probes to selectively enrich $S$. aureus with peptide HHHHHHDEEGLFVD (D) due to special properties (Kuo et al., 2016). On this basis, improvements lie in the addition of outer package to maintain long effects. For instance, a mesoporous silica nanoparticle (MSN) core was used to transport gentamicin and a cationic human antimicrobial peptide ubiquicidin (UBI29-41) to target the intracellular $S$. aureus. The lipid shell largely prevented the early release of therapeutics (Yang et al., 2018). Likewise, peptides GIBIMP5S9K (G17) and GAM019 (G19) designed through genetic algorithm optimization strategy and solid-phase chemistry were also reported to be capable of killing MRSA and E. coli O157:H7 with a slow and gradual release when encapsulated on poly-lactic-glycolic acid (PLGA) nanoparticles (Gómez-Sequeda et al., 2020).

Sometimes, the combination of nanoparticles and peptides exceeds our initial expectation. For instance, once synthesized peptide HHC10 was conjugated with nanoparticles, it showed potent antimicrobial activity against $E$. coli inside the cells by disintegrating the cell membrane and inducing apoptosis of the host simultaneously (Sharma A. et al., 2018). Also, Esc(1-21), a derivative of the frog skin AMP, targeted the free-living and biofilm forms of $P$. aeruginosa (Casciaro et al., 2017). When it was conjugated to soluble AuNPs, it had 15-fold activity of the free peptide without any toxicity.

These findings are interesting and impressive if we do not take the previous cost of peptide screening into consideration. In this combination, NPs display multiple advantages in effective transport, gradual release, reduced toxicity, and improved 
potency. However, despite these, the safety of peptide and its concentration control are still noteworthy.

\section{Membrane-Based Targeted Nanoparticles}

Breakthroughs in nanotechnology have contributed to an endless stream of synthetic nanoparticles with supreme specificity since then. Generally, precise delivery is achieved by conjugating nanoparticles with ligands ( $\mathrm{Hu}$ et al., 2017), peptides (Huang et al., 2017), and antibodies (Lambert and Berkenblit, 2018). However, increasing attention has been paid to the membrane of immune cells recently (Li et al., 2018). A study showed that coating macrophage membrane pretreated with specific bacteria onto the surface of a gold-silver nanocage (GSNC) rendered the nanosystem more efficient (Wang et al., 2018). It was mainly due to the potential interaction between bacterial recognizing receptors on macrophage membranes and distinct pathogenassociated molecular patterns (PAMPs) in bacteria. In another research, Ying et al. (2018) utilized vesicles from the cholesterolenriched platelet membrane to transport small molecule therapeutics (Figure 3C). Owing to the surface markers on the membrane, this system exhibited natural affinity to both breast cancer cells and MRSA. Meanwhile, compared to RBC-based formulations which support nonspecific improvement of drug bioavailability, platelet membrane-derived vesicles have large potential and distinct advantages for targeted therapy.

Additionally, other natural cell membranes can also be utilized. The membrane of extracellular vesicles secreted by $S$. aureus was reported to be applied to enclose nanoparticles as a natural guide (Gao et al., 2019). This well-designed complex therefore exhibited high specificity and efficacy against $S$. aureus infection in mouse models. For combating Helicobacter pylori, biomimetic nanoparticles coated with plasma membranes of gastric epithelial cells could be potent carriers for antibiotics (Angsantikul et al., 2018). They showed inherent adhesion to $H$. pylori bacteria by the same surface antigens as the source cells.

Collectively, all these designs are based on special substances on pretreated membranes, which can produce associations with the target pathogenic bacteria. This is with no doubt an ingenious approach relying on already existed associations.

\section{Other Specially-Designed Targeted Nanoparticles}

Recently, a research showed a brand-new approach to target pathogenic bacteria through the use of functionalized DNA origami nanostructures with aptamers (Mela et al., 2020). Using direct stochastic optical reconstruction microscopy (dSTORM) and atomic force microscopy (AFM), this special structure was confirmed to be capable of binding with and killing bacteria more efficiently through the lysozyme delivered on it than free lysozyme. This research indeed appeared as an innovation and offered us a potent tool in the fight against pathogenic bacteria and the following antibiotic resistance.

To sum up, both metal nanoparticles with photothermal effect and organic nanoparticles as excellent carriers exhibit large potential in precise treatment. The most attractive point lies in the nonexistence of resistance as their intrinsic properties are unique and natural. However, despite their advantages in terms of pharmacokinetics, we should admit that there are still not enough objective judgments for the safety of them, such as systemic toxicity, cytotoxicity, and influence on the blood-brain barrier.

\section{PHAGE-BASED TARGETED THERAPY}

Phage is one kind of virus that is specific to bacteria, which is abundant in our environment. At the same time, phage therapy has raised much concern since the start of the 20th century in tackling with thorny infections with its personalized characteristics. Although it seems like a novel alternative strategy against antibiotic-resistant bacteria, phages were first used in children's hospital soon after being reported by Frederick Twort in 1915 in London (Twort, 1915). Compared to traditional antibiotics, phages exhibit several advantages as they can regulate secretion at infection sites through in situ multiplication and automatic clearance (Abedon, 2011). Also, phages have minimal possibility to generate resistance as they can coevolve with the host. Notably, it has been widely acknowledged that sublethal levels of some specific antibiotics could enhance the effect of phages regardless of the resistance state. While on the other hand, defects still exist such as the activation of immune response (Nungester and Watrous, 1934), incapability in treating intracellular infections, and the subsequent bacterial resistance (Mahony et al., 2008). However, despite these factors, phage therapy has indeed made some progress in combating VRE, $\beta$-lactam-resistant Enterobacteriaceae, and MRSA, exhibiting its broad prospects in the targeted therapy (Sybesma et al., 2018).

\section{Phage Therapy}

Phage therapy, the strategy to combat with infectious bacteria by single phage or phage combination, has received outstanding achievements against a series of bacteria.

As for $S$. aureus, bacteriophage and its product such as phi 812 and AB-SA01 exhibited extensive killing ability among hundreds of strains and strong potency in vitro, respectively (Pantůcek et al., 1998; Lehman et al., 2019). Sb-1 was another promising phage as it avoided the risk of amputation for patient with diabetic foot ulcers infected with MRSA (Fish et al., 2016). Meanwhile, phage cocktails are effective as mixtures of only six different phages could tackle with the most common $S$. aureus strains (Kelly et al., 2011). Additionally, a phage cocktail of $S$. aureus, CT-SA, can potently eliminate $S$. aureus forming biofilm from chronic rhinosinusitis patients (Drilling et al., 2014). Another research on the treatment of $S$. aureus-induced mastitis also tested the efficacy of the phage cocktail composed by two phages, that is, vBSM-A1 and vBSPA2, which was comparable to that produced by ceftiofur sodium (Geng et al., 2020).

Another troublesome pathogen is A. baumannii, which was classified within the most dangerous critical priority group of MDR bacteria by the WHO in 2017. In face of this urgent circumstance, phage therapy can be an alternative strategy to fill in the vacancy of potent antibiotics. Representatives were Acibel004 and Acibel007, the bacteriophage Loki, phage vB- 
GEC_Ab-M-G7 (phi G7), and Phage IME200 (Turner et al., 2017; Liu et al., 2019). In clinical cases, phage cocktail was successfully employed by Schooley et al. (2017) to treat diabetic patients with MDR A. baumannii infections (Schooley et al., 2017). A mouse infected wound model also highlighted the efficacy of a fivemember cocktail of wild phages against A. baumannii. Interestingly, these phages seemed to work in a combinatorial manner as one constituent phage transformed capsulated $A$. baumannii into uncapsulated state. This resulted in the enhanced sensibility of $A$. baumannii to the remaining four phages (Regeimbal et al., 2016).

Then, as one of the most common opportunistic pathogens involved in nosocomial infection, $P$. aeruginosa also has its characteristic phage therapies (Driscoll et al., 2007). In a research, Waters et al. (2017) reported the efficacy of phage therapy toward a natural long-term chronic lung infection established by $P$. aeruginosa. Notably, another anti-P. aeruginosa phage OMKO1, utilizing the outer membrane porin $M$ (OprM) of the multidrug efflux systems MexAB and MexXY as its receptor-binding site, could target pathogens and avoid resistance simultaneously (Chan et al., 2016). This with no doubt provided an improvement in phage therapy where phages exerted selection for MDR bacteria, allowing the resuscitation of antibiotics with less effectiveness originally. Apart from these examples described above, phage therapy also unfolded its capabilities in other bacteria such as Mycobacterium abscessus (Dedrick et al., 2019), as well as E. coli and Proteus spp (Bernasconi et al., 2017).

\section{Combination of Antibiotic and Phage}

Recently, numerous evidences have sprung up and uncovered the evident advantages between antibiotics and phages than their single use (Chhibber et al., 2013; Kamal and Dennis, 2015). Accordingly, intrinsic antibiotic resistance is tightly associated with properties such as low drug permeability, extrusion of efflux pumps, and expression of SOS systems. Hence, phages with receptors on the membrane-exposed regions of an efflux pump system or overexpressing an SOS suppressor may act as adapters and enhancers of appropriate antibiotics in efficient killing (Chan et al., 2016). Then, a concept called phage-antibiotic synergy (PAS) effect was put forward; that is, sublethal concentrations of antibiotics could contribute to enhancement of the infectivity of phages (Comeau et al., 2007). In this case, an altered physiological state of the host caused cellular filamentation, which led to increased biosynthetic capacity of phages and external attachment to the bacterium. Recently, Shlezinger et al. (2019) in their research illustrated that the efficacy of the combined treatment of vancomycin and phage EFLK1 against VRE cultures was evidently improved compared to single-drug therapy. Also, in an effort to find out the PAS against $P$. aeruginosa in vitro, phage KPP22 was sorted out due to its PAS with a variety of antibiotics and several anti-Pseudomonas drugs, particularly piperacillin and ceftazidime (Uchiyama et al., 2018). Explanations based on Darwinian evolution illustrate the logic beneath the positive interactions (Torres-Barceló and Hochberg, 2016). First, genetic constraints or the costs force the bacteria to weigh between resistance mechanisms. Second, the direct negative interaction between resistance mechanisms impedes the evolution of resistance. Third, it is just the low bacterial densities that reduce the possibility of the appearance of resistance mutations.

\section{CRISPR-CAS9 TECHNOLOGY-BASED TARGETED THERAPY}

CRISPR-Cas9 system, a protective barrier of acquired immunity found in numerous bacteria and archaea, has received much attention since it was discovered (Doudna and Charpentier, 2014). It includes a CRISPR loci with short repeated sequences (repeats) and similarly sized flanking sequences (spacers), as well as genes encoding Cas-related proteins. These spacers, usually foreign DNA or RNA element, will be inserted in the loci and then be used as guides for Cas protein to perform cutting capability during next invasive incident with the same sequence. Of all the CRISPR-Cas9 systems, Type II CRISPRCas9 system is one of the best described and exhibits nonignorable potential in gene editing (Wang et al., 2016). Also, it has been regarded as a precise approach to overcome bacterial infections by selectively targeting genes such as biofilm formation and virulence (De La Fuente-Núñ ez and Lu, 2017). Despite its broad prospects, Type II CRISPR-Cas9 system still encounters a large barrier in its further development, that is, the lack of efficient delivery vector. However, this bottleneck has been broken through the development of nanotechnology, genetic recombination, and engineered phages (Figure 4).

In research of Rodrigues, the CRISPR-Cas system was adapted into a constitutively expressed module encoded on a pheromoneresponsive conjugative plasmid. It was subsequently transferred to E. faecalis for the selective removal of antibiotic resistance genes (Rodrigues et al., 2019). A similar experiment conducted by Dong et al. (2019) also removed the plasmid harboring $\mathrm{mcr}$ - 1 effectively. Additionally, Kim et al. (2018) succeeded in searching for a conserved target sequence for CRISPR/Cas9 among numerous ESBL mutants. And the later constructed conjugative plasmids expressing both Cas9 protein and sgRNA could resensitize MDR E. coli whose resistance was determined by other genes.

As the alternative, phage-delivered CRISPR targeting also attaches much attention. Liu et al. (2020) integrated the CRISPR/Cas9 system into the genome of a lysogenic phage through novel cloning methods. Then, a phage-delivered resistance eradication with a subsequent antibiotic treatment (PRESA) strategy came out. It displayed multiple advantages such as high plasmid-clearance efficacy, constant inhibition effect, and little or no mutation frequency. Likewise, combining the CRISPR/Cas9 system with a temperate phage, Park et al. (2017) successfully designed a potent weapon with an extended host range of $S$. aureus by eliminating major virulence genes in chromosome. Work of Cobb et al. (2019) achieved similar results against infections caused by $S$. aureus producing biofilm.

Another option is the involvement of nanotechnology. For example, Kang et al. designed a polymer-derived Cas9, which was then combined with targeted single-guide RNA to generate nanosized CRISPR complexes. This complex could target 


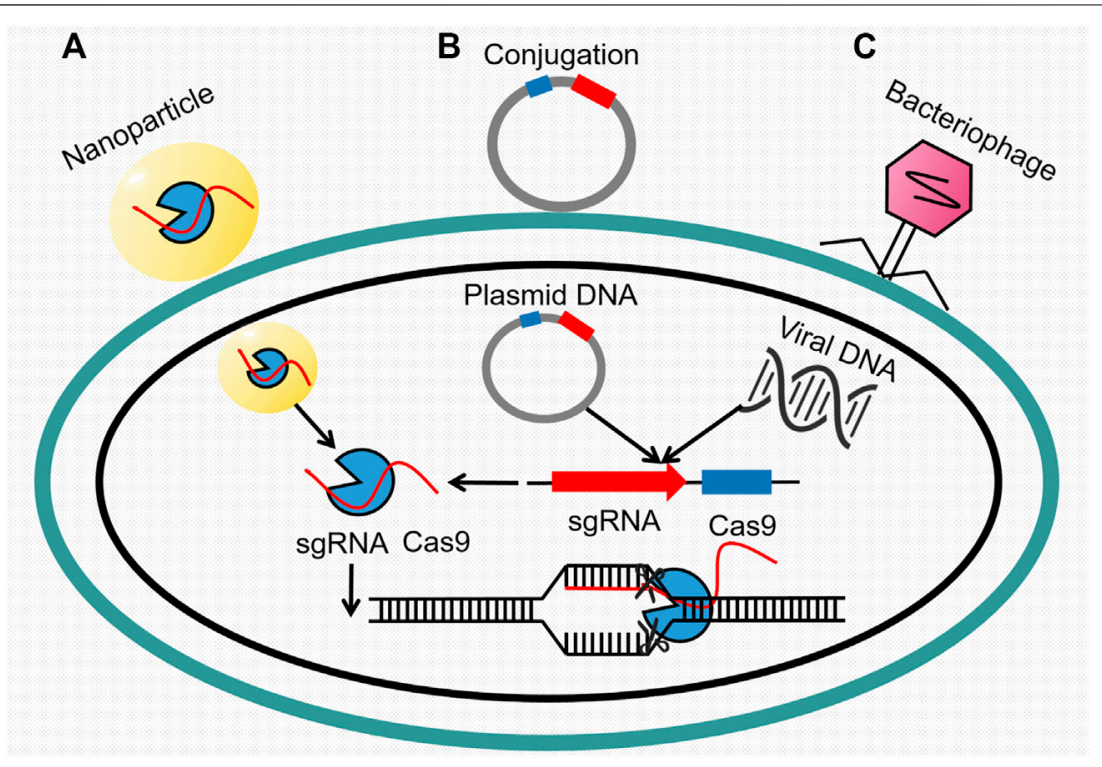

FIGURE 4 | Transport of the CRISPR Cas9 system through three approaches. (A) Nanoparticles carrying single-guide RNA and Cas9 protein, (B) plasmid DNA through conjugation, and (C) viral DNA through bacteriophage invasion make up the main sources of the acquired Cas 9 system in target bacterial cell. Thereafter, sgRNA recognizes the specific resistance gene segments in chromosomal DNA, and Cas9 protein conducts cutting activity.

$m e c A$, the major gene associated with methicillin resistance of MRSA (Kang et al., 2017). The discovery of CRISPR-Cas technology is really a milestone event in history of genomic editing. Meanwhile, it is still a long march before applying it to clinical treatment even its delivery has been largely improved. What we should seriously consider is how to deal with the more complex gene editing, how to decrease the "off-target" mutations, and most importantly, how to shrink the high cost.

\section{CHALLENGES AND OUTLOOKS}

Throughout the context, we put our emphasis on five mainstream antimicrobial strategies and exemplify their feasibility and effectiveness. However, despite their great prospects, obstacles that prevent them from entering into clinic and getting growing popularity are still assignable.

Narrow-spectrum antimicrobials meet their bottlenecks due to the frequent single-target resistance mutations and the risk of prescriptions with precise agents to save patients under critical conditions considering the lag in contemporary pathogen diagnosis and antibacterial spectrum determination. As for bacteriophages, large-scaled sequencing in the early stage requires substantial front input. The clearance by innate immune system directly affects the phage pharmacokinetics. Besides, difficulties in penetrating into mammalian cells, uncertainty in safety, and the increasing resistance are indeed confusing hindrances (Oechslin, 2018). Relatively speaking, probiotics are much safer, but this kind of safety differs from bacteria to bacteria, person to person, and quantity to quantity. Longtime use of artificial probiotics inevitably induces dependence so that our gut will gradually lose the ability to generate its own probiotics. The abuse of probiotic supplements also results in side effects such as infections, metabolic disorder, and abnormal immune functions (Suez et al., 2019). Nanoparticles come to people's attention with excellent performance, while their syntheses have high standards, which are not appropriate for extensive industrial production. Also, uncertainties in terms of storage, dispersion, stability, cytotoxicity, and degradation are huge hindrances in the way of their advancements. Last but not least, CRISPR-Cas technology is reliable, but sometimes, the "off-target" phenomenon will happen, which largely affects gene editing efficiency (Pursey et al., 2018).

Hopefully, some improvements have been put forward to overcome these challenges. For instance, the application of nucleic acid or mass spectrometry-based technologies greatly accelerates the diagnosis of pathogens prior to prescription of narrow-spectrum antimicrobials. Also, in order to avoid mutations induced by genetic modification during culturing process before administration, inducible repression systems are well designed in engineered probiotics to regulate the expression of functional genes. As for bacteriophages, encapsulating the phage in liposomes and nonimmunogenic polyethylene glycol can improve its in vivo stability against the acidic and proteolytic environment and escape from the elimination of the innate immune system, respectively (Kim et al., 2008). Then, the drawbacks of CRISPR-Cas technology have been tackled by target multiplexing and tailored CRISPR-Cas delivery.

All along, what numerous scientists focus on is to avoid the terrible influence of bacterial pathogenicity and subsequent resistance as their combinations may cause incredible bad results. For example, Europe in May 2011 witnessed the outbreak of hemolytic uremic syndrome related to $E$. coli serotype O104: $\mathrm{H} 4$, leaving thousands of people under threats 
TABLE 2 | Typical antibodies against four pathogenic bacteria in drug development.

\begin{tabular}{|c|c|c|c|c|c|}
\hline Antibodies & Pathogens & Targets & Company & $\begin{array}{l}\text { Clinical } \\
\text { studied }\end{array}$ & References \\
\hline Raxibacumab & B. anthracis & Protective antigen & GlaxoSmith Kline & FDA approved & $\begin{array}{l}\text { Subramanian et al. } \\
\text { (2005) }\end{array}$ \\
\hline Obiltoxaximab & B. anthracis & Protective antigen & Elusys Therapeutics & FDA approved & Hou and Morrill (2017) \\
\hline Bezlotoxumab & C. difficile & Toxin B & Merck \& Co. & Phase III & Wilcox et al. (2017) \\
\hline Actoxumab & C. difficile & Toxin A & Merck \& Co. & Phase III & Hernandez et al. (2017) \\
\hline Panobacumab & $P$. aeruginosa & LPS O antigen (011) & Kenta Biotech & Phase I//II & Lazar et al. (2009) \\
\hline MEDI-3902 & $P$. aeruginosa & $\begin{array}{l}\text { PcrV type III secretion system (T3SS) and persistence } \\
\text { factor Psl }\end{array}$ & Medlmmune & Phase II & Ali et al. (2015) \\
\hline $\begin{array}{l}\text { Anti- } \\
\text { pseudomonas IgY }\end{array}$ & $P$. aeruginosa & Immunsystem AB & Unknown & Phase I/II & Thomsen et al. (2016) \\
\hline MEDI-4893 & Staphylococci & Alpha toxin & Medlmmune & Phase ॥ & Yu et al. (2017) \\
\hline Pagibaximab & Staphylococci & Lipoteichoic acid & Biosynexus & Phase III & $\begin{array}{l}\text { Patel and Kaufman } \\
\text { (2015) }\end{array}$ \\
\hline Aurexis & Staphylococci & Clumping factor $\mathrm{A}$ & $\begin{array}{l}\text { Bristol-Meyrs } \\
\text { Squibb }\end{array}$ & Phase ॥ & Weems et al. (2006) \\
\hline
\end{tabular}

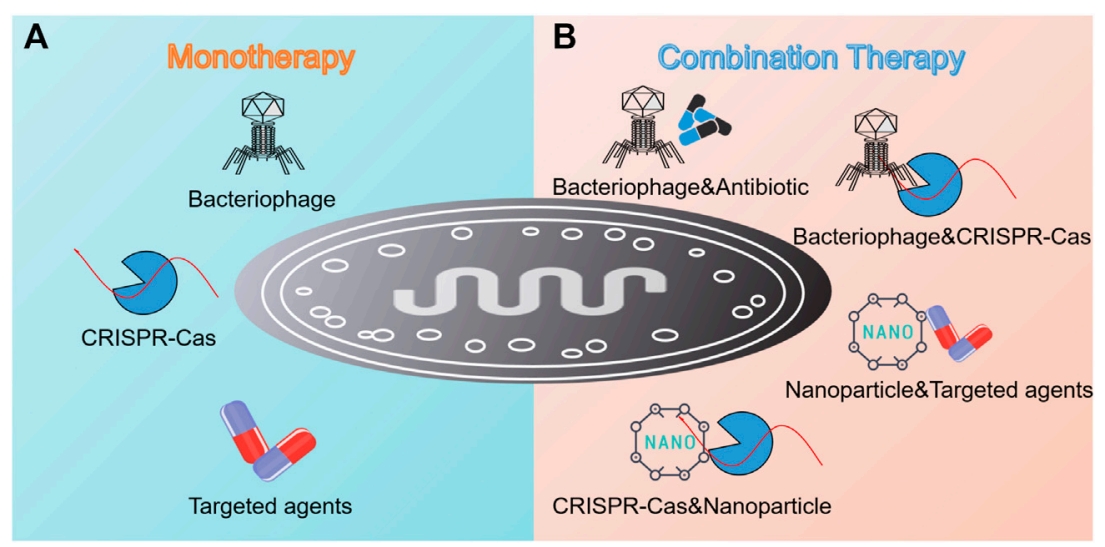

FIGURE 5 | Summary of targeted monotherapy and combination therapy against pathogenic bacteria. (A) Monotherapy involves the invasion of bacteriophage, the employment of CRISPR-Cas technology, and the utilization of targeted antimicrobial agents such as antibiotics, lysins, antibodies, and AMPs. (B) Combination therapy shows its advantages as reflected in the combination of bacteriophage and antibiotic, bacteriophage and CRISPR-Cas technology, nanoparticles and targeted antimicrobial agents, and CRISPR-Cas technology and nanoparticles.

(Buchholz et al., 2011). So in our endeavor to fight against pathogenic bacteria, we should be on guard against the potential evolution of resistance. Comfortingly, as we described above, the appropriate combinations of phages and antibiotics well restore the efficacy of antibiotics, and the PAS effect under sublethal concentrations of antibiotics heavily enhance the infectivity of phages. Additionally, engineered probiotics utilizing quorum sensing to realize targeted killing add minimal burden to the host due to their commensal relationship, which circumvents the emergence of resistance. Also noteworthy are nanoparticles, as they hardly induce resistance due to their natural physical properties.

\section{CONCLUSIONS}

The increasing resistance crisis calls for novel antimicrobial pipelines, particularly for targeted therapeutic strategies. In this review, an overview of five promising targeted regimens including narrow-spectrum agents, engineered probiotics, nanotechnology, phage therapy, and CRISPR-Cas9 technology was provided. In addition, antibody is another example we have not illustrated sufficiently in the context, but it is of the same weight as others. Until recently, several antibodies against Staphylococci, P. aeruginosa, B. anthracis, and $C$. difficile have been approved for clinical use or are still in different phases of Clinical Efficacy Testing (Table 2). In terms of all strategies mentioned above, they can be divided into two main categories, that is, monotherapy and combination therapy (Figure 5). Usually, the efficacy of the latter exceeds that of the former due to high delivery efficiency, enough local concentration, synergistic effect, and low resistance frequency.

Nevertheless, it makes great sense to deepen the current knowledge about these innovative therapeutic strategies because they are not mature, stable, and reliable enough at 
present. Although these endeavors would be time-consuming, labor-intensive, and probably limited to laboratories, they are indeed meaningful as currently effective antimicrobials will end up losing their activities someday. Considering that antibiotic resistance has become a global concern, we firmly believe that with the advancement of technology, great progress will be made in these works.

\section{AUTHOR CONTRIBUTIONS}

All authors listed have made a substantial, direct, and intellectual contribution to the work and approved it for publication.

\section{REFERENCES}

Abedon, S. (2011). Phage Therapy Pharmacology: Calculating Phage Dosing. Adv. Appl. Microbiol. 77, 1-40. doi:10.1016/b978-0-12-387044-5.00001-7

Ali, M., Nelson, A. R., Lopez, A. L., and Sack, D. A. (2015). Updated Global Burden of Cholera in Endemic Countries. Plos. Negl. Trop. D. 9, e0003832. doi:10.1371/ journal.pntd.0003832

Angsantikul, P., Thamphiwatana, S., Zhang, Q., Spiekermann, K., Zhuang, J., Fang, R. H., et al. (2018). Coating Nanoparticles with Gastric Epithelial Cell Membrane for Targeted Antibiotic Delivery against Helicobacter pylori Infection. Adv. Therap. 1, 1800016. doi:10.1002/adtp.201800016

Bernasconi, O. J., Donà, V., Tinguely, R., and Endimiani, A. (2017). In vitro activity of Three Commercial Bacteriophage Cocktails against Multidrug-Resistant Escherichia coli and Proteus Spp. Strains of Human and Non-human Origin. J. Glob. Antimicrob. Resist. 8, 179-185. doi:10.1016/j.jgar.2016.12.013

Blaser, M. J. (2016). Antibiotic Use and its Consequences for the Normal Microbiome. Science 352, 544-545. doi:10.1126/science.aad9358

Braunstein, A., Papo, N., and Shai, Y. (2004). In vitro activity and Potency of an Intravenously Injected Antimicrobial Peptide and its DL Amino Acid Analog in Mice Infected with Bacteria. Aac 48, 3127-3129. doi:10.1128/aac.48.8.31273129.2004

Buchholz, U., Bernard, H., Werber, D., Böhmer, M. M., Remschmidt, C., Wilking, H., et al. (2011). German Outbreak of Escherichia coli O104:H4 Associated with Sprouts. N. Engl. J. Med. 365, 1763-1770. doi:10.1056/nejmoal106482

Carlet, J., and Mainardi, J.-L. (2012). Antibacterial Agents: Back to the Future? Can We Live with Only Colistin, Co-trimoxazole and Fosfomycin? Clin. Microbiol. Infect. 18, 1-3. doi:10.1111/j.1469-0691.2011.03702.x

Casciaro, B., Moros, M., Rivera-Fernández, S., Bellelli, A., De La Fuente, J. M., and Mangoni, M. L. (2017). Gold-nanoparticles Coated with the Antimicrobial Peptide Esculentin-1a(1-21)NH 2 as a Reliable Strategy for Antipseudomonal Drugs. Acta Biomater. 47, 170-181. doi:10.1016/j.actbio.2016.09.041

Chan, B. K., Sistrom, M., Wertz, J. E., Kortright, K. E., Narayan, D., and Turner, P. E. (2016). Phage Selection Restores Antibiotic Sensitivity in MDR Pseudomonas aeruginosa. Sci. Rep. 6, 26717. doi:10.1038/srep26717

Chang, W., Small, D. A., Toghrol, F., and Bentley, W. E. (2005). Microarray Analysis of Toxicogenomic Effects of Peracetic Acid onPseudomonas Aeruginosa. Environ. Sci. Technol. 39, 5893-5899. doi:10.1021/es0503534

Chappell, T. C., and Nair, N. U. (2020). Engineered Lactobacilli Display Antibiofilm and Growth Suppressing Activities against Pseudomonas aeruginosa. NPJ Biofilms Microbiomes 6, 48. doi:10.1038/s41522-020-00156-6

Chhibber, S., Kaur, T., and Sandeep, K. (2013). Co-therapy Using Lytic Bacteriophage and Linezolid: Effective Treatment in Eliminating Methicillin Resistant Staphylococcus aureus (MRSA) from Diabetic Foot Infections. PLoS One 8, e56022. doi:10.1371/journal.pone.0056022

Chou, S., Wang, J., Shang, L., Akhtar, M. U., Wang, Z., Shi, B., et al. (2019). Short, Symmetric-Helical Peptides Have Narrow-Spectrum Activity with Low Resistance Potential and High Selectivity. Biomater. Sci. 7, 2394-2409. doi:10.1039/c9bm00044e

Cobb, L. H., Park, J., Swanson, E. A., Beard, M. C., Mccabe, E. M., Rourke, A. S., et al. (2019). CRISPR-Cas9 Modified Bacteriophage for Treatment of

\section{FUNDING}

This work was supported by the National Natural Science Foundation of China (32002331), National Key Research and Development Program of China (2018YFA0903400), the Natural Science Foundation of Jiangsu Province of China (BK20190893), the Agricultural Science and Technology Independent Innovation Fund of Jiangsu Province (CX(20)3091), China Postdoctoral Science Foundation funded project (2019M651984), a project funded by the Priority Academic Program Development of Jiangsu Higher Education Institutions (PAPD), and Lift Engineering of Young Talents of Jiangsu Association for Science and Technology.

Staphylococcus aureus Induced Osteomyelitis and Soft Tissue Infection. PLoS One 14, e0220421. doi:10.1371/journal.pone.0220421

Cochrane, S. A., Findlay, B., Bakhtiary, A., Acedo, J. Z., Rodriguez-Lopez, E. M., Mercier, P., et al. (2016). Antimicrobial Lipopeptide Tridecaptin Alselectively Binds to Gram-Negative Lipid II. Proc. Natl. Acad. Sci. U.S.A. 113, 11561-11566. doi:10.1073/pnas.1608623113

Collin, F., and Maxwell, A. (2019). The Microbial Toxin Microcin B17: Prospects for the Development of New Antibacterial Agents. J. Mol. Biol. 431, 3400-3426. doi:10.1016/j.jmb.2019.05.050

Comeau, A. M., Tétart, F., Trojet, S. N., Prère, M.-F., and Krisch, H. M. (2007). Phage-Antibiotic Synergy (PAS): $\beta$-Lactam and Quinolone Antibiotics Stimulate Virulent Phage Growth. PLoS One 2, e799. doi:10.1371/journal. pone. 0000799

Culp, E. J., Waglechner, N., Wang, W., Fiebig-Comyn, A. A., Hsu, Y.-P., Koteva, K., et al. (2020). Evolution-guided Discovery of Antibiotics that Inhibit Peptidoglycan Remodelling. Nature 578, 582-587. doi:10.1038/s41586-0201990-9

Daniel, A., Euler, C., Collin, M., Chahales, P., Gorelick, K. J., and Fischetti, V. A. (2010). Synergism between a Novel Chimeric Lysin and Oxacillin Protects against Infection by Methicillin-Resistant Staphylococcus aureus. Aac 54, 1603-1612. doi:10.1128/aac.01625-09

De La Fuente-Núñez, C., and Lu, T. K. (2017). CRISPR-Cas9 Technology: Applications in Genome Engineering, Development of Sequence-specific Antimicrobials, and Future Prospects. Integr. Biol. 9, 109-122. doi:10.1039/ c6ib00140h

Dedrick, R. M., Guerrero-Bustamante, C. A., Garlena, R. A., Russell, D. A., Ford, K., Harris, K., et al. (2019). Engineered Bacteriophages for Treatment of a Patient with a Disseminated Drug-Resistant Mycobacterium Abscessus. Nat. Med. 25, 730-733. doi:10.1038/s41591-019-0437-z

Dong, H., Xiang, H., Mu, D., Wang, D., and Wang, T. (2019). Exploiting a Conjugative CRISPR/Cas9 System to Eliminate Plasmid Harbouring the Mcr-1 Gene from Escherichia coli. Int. J. Antimicrob. Agents 53, 1-8. doi:10.1016/j. ijantimicag.2018.09.017

Doudna, J. A., and Charpentier, E. (2014). The New Frontier of Genome Engineering with CRISPR-Cas9. Science 346, 1258096. doi:10.1126/science. 1258096

Drilling, A., Morales, S., Jardeleza, C., Vreugde, S., Speck, P., and Wormald, P.-J. (2014). Bacteriophage Reduces Biofilm of Staphylococcus aureus Ex Vivo Isolates from Chronic Rhinosinusitis Patients. Am. J. Rhinol allergy 28, 3-11. doi:10.2500/ajra.2014.28.4001

Driscoll, J. A., Brody, S. L., and Kollef, M. H. (2007).The Epidemiology, Pathogenesis and Treatment of Pseudomonas aeruginosa Infections, Drugs. 67. 351-368. doi:10.2165/00003495-200767030-00003

Duan, F., and March, J. C. (2010). Engineered Bacterial Communication Prevents Vibrio cholerae Virulence in an Infant Mouse Model. Proc. Natl. Acad. Sci. 107, 11260-11264. doi:10.1073/pnas.1001294107

Fischetti, V. A. (2008). Bacteriophage Lysins as Effective Antibacterials. Curr. Opin. Microbiol. 11, 393-400. doi:10.1016/j.mib.2008.09.012

Fish, R., Kutter, E., Wheat, G., Blasdel, B., Kutateladze, M., and Kuhl, S. (2016). Bacteriophage Treatment of Intransigent Diabetic Toe Ulcers: a Case Series. J. Wound Care 25, S27-S33. doi:10.12968/jowc.2016.25.7.s27 
Focareta, A., Paton, J. C., Morona, R., Cook, J., and Paton, A. W. (2006). A Recombinant Probiotic for Treatment and Prevention of Cholera. Gastroenterology 130, 1688-1695. doi:10.1053/j.gastro.2006.02.005

Gaeng, S., Scherer, S., Neve, H., and Loessner, M. J. (2000). Gene Cloning and Expression and Secretion ofListeria Monocytogenes Bacteriophage-Lytic Enzymes inLactococcus Lactis. Appl. Environ. Microbiol. 66, 2951-2958. doi:10.1128/aem.66.7.2951-2958.2000

Gao, F., Xu, L., Yang, B., Fan, F., and Yang, L. (2019). Kill the Real with the Fake: Eliminate IntracellularStaphylococcus aureusUsing Nanoparticle Coated with its Extracellular Vesicle Membrane as Active-Targeting Drug Carrier. ACS Infect. Dis. 5, 218-227. doi:10.1021/acsinfecdis.8b00212

Geldart, K. G., Kommineni, S., Forbes, M., Hayward, M., Dunny, G. M., Salzman, N. H., et al. (2018). EngineeredE. coliNissle 1917 for the Reduction of Vancomycin-resistantEnterococcusin the Intestinal Tract. Bioeng. Translational Med. 3, 197-208. doi:10.1002/btm2.10107

Geng, H., Zou, W., Zhang, M., Xu, L., Liu, F., Li, X., et al. (2020). Evaluation of Phage Therapy in the Treatment of Staphylococcus Aureus-Induced Mastitis in Mice. Folia. Microbiol. 65, 339-351. doi:10.1007/s12223-019-00729-9

Gómez-Sequeda, N., Ruiz, J., Ortiz, C., Urquiza, M., and Torres, R. (2020). Potent and Specific Antibacterial Activity against Escherichia coli O157:H7 and Methicillin Resistant Staphylococcus aureus (MRSA) of G17 and G19 Peptides Encapsulated into Poly-Lactic-Co-Glycolic Acid (PLGA) Nanoparticles. Antibiotics, 9. 384. doi:10.3390/antibiotics9070384

Gonzales, R. D., Schreckenberger, P. C., Graham, M. B., Kelkar, S., Denbesten, K., and Quinn, J. P. (2001). Infections Due to Vancomycin-Resistant Enterococcus Faecium Resistant to Linezolid. The Lancet 357, 1179. doi:10.1016/s01406736(00)04376-2

Hamamoto, H., Urai, M., Ishii, K., Yasukawa, J., Paudel, A., Murai, M., et al. (2015). Lysocin E Is a New Antibiotic that Targets Menaquinone in the Bacterial Membrane. Nat. Chem. Biol. 11, 127-133. doi:10.1038/nchembio.1710

Hashemian, S. M., Farhadi, T., and Ganjparvar, M. (2018). Linezolid: a Review of its Properties, Function, and Use in Critical Care. Dddt Vol. 12, 1759-1767. doi:10.2147/dddt.s164515

Heidary, M., Khosravi, A. D., Khoshnood, S., Nasiri, M. J., Soleimani, S., and Goudarzi, M. (2018). Daptomycin. Daptomycin. J. Antimicrob. Chemother. 73, 1-11. doi:10.1093/jac/dkx349

Hernandez, L. D., Kroh, H. K., Hsieh, E., Yang, X., Beaumont, M., Sheth, P. R., et al. (2017). Epitopes and Mechanism of Action of the Clostridium difficile Toxin A-Neutralizing Antibody Actoxumab. J. Mol. Biol. 429, 1030-1044. doi:10. 1016/j.jmb.2017.02.010

Hou, A. W., and Morrill, A. M. (2017). Obiltoxaximab: Adding to the Treatment Arsenal for Bacillus Anthracis Infection. Ann. Pharmacother. 51, 908-913. doi:10.1177/1060028017713029

Hu, D., Li, H., Wang, B., Ye, Z., Lei, W., Jia, F., et al. (2017). Surface-adaptive Gold Nanoparticles with Effective Adherence and Enhanced Photothermal Ablation of Methicillin-Resistant Staphylococcus aureus Biofilm. ACS Nano 11, 9330-9339. doi:10.1021/acsnano.7b04731

Huang, N., Chen, X., Zhu, X., Xu, M., and Liu, J. (2017). Ruthenium Complexes/ polypeptide Self-Assembled Nanoparticles for Identification of Bacterial Infection and Targeted Antibacterial Research. Biomaterials 141, 296-313. doi:10.1016/j.biomaterials.2017.07.005

Hussain, S., Joo, J., Kang, J., Kim, B., Braun, G. B., She, Z.-G., et al. (2018). Antibiotic-loaded Nanoparticles Targeted to the Site of Infection Enhance Antibacterial Efficacy. Nat. Biomed. Eng. 2, 95-103. doi:10.1038/s41551-0170187-5

Hwang, I. Y., Koh, E., Wong, A., March, J. C., Bentley, W. E., Lee, Y. S., et al. (2017). Engineered Probiotic Escherichia coli Can Eliminate and Prevent Pseudomonas aeruginosa Gut Infection in Animal Models. Nat. Commun. 8, 15028. doi:10. 1038/ncomms 15028

Imai, Y., Meyer, K. J., Iinishi, A., Favre-Godal, Q., Green, R., Manuse, S., et al. (2019). A New Antibiotic Selectively Kills Gram-Negative Pathogens. Nature 576, 459-464. doi:10.1038/s41586-019-1791-1

Isolauri, E., Kirjavainen, P. V., and Salminen, S. (2002). Probiotics: a Role in the Treatment of Intestinal Infection and Inflammation? Gut 50 (Suppl. 3), Iii54-iii59. doi:10.1136/gut.50.suppl_3.iii54

Jado, I., López, R., García, E., Fenoll, A., Casal, J., and García, P. (2003). Phage Lytic Enzymes as Therapy for Antibiotic-Resistant Streptococcus Pneumoniae
Infection in a Murine Sepsis Model. J. Antimicrob. Chemother. 52, 967-973. doi:10.1093/jac/dkg485

Jenssen, H., Hamill, P., and Hancock, R. E. W. (2006). Peptide Antimicrobial Agents. Cmr 19, 491-511. doi:10.1128/cmr.00056-05

Jeyaraj Pandian, C., Palanivel, R., and Balasundaram, U. (2017). Green Synthesized Nickel Nanoparticles for Targeted Detection and Killing of S. typhimurium. J. Photochem. Photobiol. B: Biol. 174, 58-69. doi:10.1016/j.jphotobiol.2017. 07.014

Kamal, F., and Dennis, J. J. (2015). Burkholderia Cepacia Complex PhageAntibiotic Synergy (PAS): Antibiotics Stimulate Lytic Phage Activity. Appl. Environ. Microbiol. 81, 1132-1138. doi:10.1128/aem.02850-14

Kang, Y. K., Kwon, K., Ryu, J. S., Lee, H. N., Park, C., and Chung, H. J. (2017). Nonviral Genome Editing Based on a Polymer-Derivatized CRISPR Nanocomplex for Targeting Bacterial Pathogens and Antibiotic Resistance. Bioconjug. Chem. 28, 957-967. doi:10.1021/acs.bioconjchem.6b00676

Kelly, D., Mcauliffe, O., O’Mahony, J., Coffey, A., and Coffey, A. (2011). Development of a Broad-Host-Range Phage Cocktail for Biocontrol. Bioengineered Bugs 2, 31-37. doi:10.4161/bbug.2.1.13657

Kim, D., Kwon, S.-J., Sauve, J., Fraser, K., Kemp, L., Lee, I., et al. (2019). Modular Assembly of Unique Chimeric Lytic Enzymes on a Protein Scaffold Possessing Anti-staphylococcal Activity. Biomacromolecules 20, 4035-4043. doi:10.1021/ acs.biomac.9b01134

Kim, D., Kwon, S.-J., Wu, X., Sauve, J., Lee, I., Nam, J., et al. (2018). Selective Killing of Pathogenic Bacteria by Antimicrobial Silver Nanoparticle-Cell Wall Binding Domain Conjugates. ACS Appl. Mater. Inter. 10, 13317-13324. doi:10.1021/ acsami.8b00181

Kim, K.-P., Cha, J.-D., Jang, E.-H., Klumpp, J., Hagens, S., Hardt, W.-D., et al. (2008). PEGylation of Bacteriophages Increases Blood Circulation Time and Reduces T-Helper Type 1 Immune Response. Microb. Biotechnol. 1, 247-257. doi:10.1111/j.1751-7915.2008.00028.x

Kling, A., Lukat, P., Almeida, D. V., Bauer, A., Fontaine, E., Sordello, S., et al. (2015). Targeting DnaN for Tuberculosis Therapy Using Novel Griselimycins. Science 348, 1106-1112. doi:10.1126/science.aaa4690

Korpela, K., Salonen, A., Virta, L. J., Kekkonen, R. A., Forslund, K., Bork, P., et al. (2016). Intestinal Microbiome Is Related to Lifetime Antibiotic Use in Finnish Pre-school Children. Nat. Commun. 7, 10410. doi:10.1038/ ncomms 10410

Kotzampassi, K., and Giamarellos-Bourboulis, E. J. (2012). Probiotics for Infectious Diseases: More Drugs, Less Dietary Supplementation. Int. J. Antimicrob. Agents 40, 288-296. doi:10.1016/j.ijantimicag.2012.06.006

Kuo, F.-Y., Lin, W.-L., and Chen, Y.-C. (2016). Affinity Capture Using PeptideFunctionalized Magnetic Nanoparticles to Target Staphylococcus aureus. Nanoscale 8, 9217-9225. doi:10.1039/c6nr00368k

Lambert, J. M., and Berkenblit, A. (2018). Antibody-drug Conjugates for Cancer Treatment. Annu. Rev. Med. 69, 191-207. doi:10.1146/annurev-med-061516121357

Larpin, Y., Oechslin, F., Moreillon, P., Resch, G., Entenza, J. M., and Mancini, S. (2018). In vitro characterization of PlyE146, a Novel Phage Lysin that Targets Gram-Negative Bacteria. PLoS One 13, e0192507. doi:10.1371/journal.pone. 0192507

Laviña, M., Gaggero, C., and Moreno, F. (1990). Microcin H47, a ChromosomeEncoded Microcin Antibiotic of Escherichia coli. J. Bacteriol. 172, 6585-6588. doi:10.1128/jb.172.11.6585-6588.1990

Lazar, H., Horn, M. P., Zuercher, A. W., Imboden, M. A., Durrer, P., Seiberling, M., et al. (2009). Pharmacokinetics and Safety Profile of the Human AntiPseudomonas aeruginosa Serotype O11 Immunoglobulin M Monoclonal Antibody KBPA-101 in Healthy Volunteers. Aac 53, 3442-3446. doi:10. 1128/aac.01699-08

Lazzaro, B. P., Zasloff, M., and Rolff, J. (2020). Antimicrobial Peptides: Application Informed by Evolution. Science 368, eaau5480. doi:10.1126/science.aau5480

Lehman, S., Mearns, G., Rankin, D., Cole, R., Smrekar, F., Branston, S., et al. (2019). Design and Preclinical Development of a Phage Product for the Treatment of Antibiotic-Resistant Staphylococcus aureus Infections. Viruses 11, 88. doi:10. 3390/v11010088

Li, J., Angsantikul, P., Liu, W., Esteban-Fernández De Ávila, B., Chang, X., Sandraz, E., et al. (2018). Biomimetic Platelet-Camouflaged Nanorobots for Binding and Isolation of Biological Threats. Adv. Mater. 30. doi:10.1002/adma.201704800 
Lilly, D. M., and Stillwell, R. H. (1965). Probiotics: Growth-Promoting Factors Produced by Microorganisms. Science 147, 747-748. doi:10.1126/science.147. 3659.747

Ling, L. L., Schneider, T., Peoples, A. J., Spoering, A. L., Engels, I., Conlon, B. P., et al. (2015). A New Antibiotic Kills Pathogens without Detectable Resistance. Nature 517, 455-459. doi:10.1038/nature14098

Liu, H., Li, H., Liang, Y., Du, X., Yang, C., Yang, L., et al. (2020). Phage-delivered Sensitisation with Subsequent Antibiotic Treatment Reveals Sustained Effect against Antimicrobial Resistant Bacteria. Theranostics 10, 6310-6321. doi:10. 7150/thno.42573

Liu, Y., Ding, S., Dietrich, R., Märtlbauer, E., and Zhu, K. (2017). A BiosurfactantInspired Heptapeptide with Improved Specificity to Kill MRSA. Angew. Chem. Int. Ed. 56, 1486-1490. doi:10.1002/anie.201609277

Liu, Y., Mi, Z., Mi, L., Huang, Y., Li, P., Liu, H., et al. (2019). Identification and Characterization of Capsule Depolymerase Dpo48 from Acinetobacter Baumannii Phage IME200. PeerJ 7, e6173. doi:10.7717/peerj.6173

Liu, Y., Shi, J., Tong, Z., Jia, Y., Yang, B., and Wang, Z. (2021). The Revitalization of Antimicrobial Peptides in the Resistance Era. Pharmacol. Res. 163, 105276. doi:10.1016/j.phrs.2020.105276

Ma, B., Fang, C., Lu, L., Wang, M., Xue, X., Zhou, Y., et al. (2019). The Antimicrobial Peptide Thanatin Disrupts the Bacterial Outer Membrane and Inactivates the NDM-1 Metallo- $\beta$-Lactamase. Nat. Commun. 10, 3517. doi:10.1038/s41467-019-11503-3

Ma, J., Huang, H., Xie, Y., Liu, Z., Zhao, J., Zhang, C., et al. (2017). Biosynthesis of Ilamycins Featuring Unusual Building Blocks and Engineered Production of Enhanced Anti-tuberculosis Agents. Nat. Commun. 8, 391. doi:10.1038/s41467017-00419-5

Mahony, J., Mcgrath, S., Fitzgerald, G. F., and Van Sinderen, D. (2008). Identification and Characterization of Lactococcal-Prophage-Carried Superinfection Exclusion Genes. Aem 74, 6206-6215. doi:10.1128/aem. 01053-08

Mao, N., Cubillos-Ruiz, A., Cameron, D. E., and Collins, J. J. (2018). Probiotic Strains Detect and Suppress Cholera in Mice. Sci. Transl Med. 10. doi:10.1126/ scitranslmed.aao2586

Mastroeni, P., and Sheppard, M. (2004). Salmonella Infections in the Mouse Model: Host Resistance Factors and In Vivo Dynamics of Bacterial Spread and Distribution in the Tissues. Microbes Infect. 6, 398-405. doi:10.1016/j.micinf. 2003.12.009

McGowan, S., Buckle, A. M., Mitchell, M. S., Hoopes, J. T., Gallagher, D. T., Heselpoth, R. D., et al. (2012). X-ray Crystal Structure of the Streptococcal Specific Phage Lysin PlyC. Proc. Natl. Acad. Sci. 109, 12752-12757. doi:10.1073/ pnas. 1208424109

Mela, I., Vallejo-Ramirez, P. P., Makarchuk, S., Christie, G., Bailey, D., Henderson, R. M., et al. (2020). DNA Nanostructures for Targeted Antimicrobial Delivery. Angew. Chem. Int. Ed. 59, 12698-12702. doi:10.1002/anie.202002740

Millenbaugh, N., Baskin, J., Desilva, M., Elliott, W. R., and Glickman, R. (2015). Photothermal Killing of Staphylococcus aureus Using Antibody-Targeted Gold Nanoparticles. Ijn 10, 1953-1960. doi:10.2147/ijn.s76150

Miller, M. B., Skorupski, K., Lenz, D. H., Taylor, R. K., and Bassler, B. L. (2002). Parallel Quorum Sensing Systems Converge to Regulate Virulence in Vibrio cholerae. Cell 110, 303-314. doi:10.1016/s0092-8674(02)00829-2

Mo, T., Ji, X., Yuan, W., Mandalapu, D., Wang, F., Zhong, Y., et al. (2019). Thuricin Z: A Narrow-Spectrum Sactibiotic that Targets the Cell Membrane. Angew. Chem. Int. Ed. 58, 18793-18797. doi:10.1002/anie.201908490

Molohon, K. J., Blair, P. M., Park, S., Doroghazi, J. R., Maxson, T., Hershfield, J. R., et al. (2016). Plantazolicin Is an Ultra-narrow Spectrum Antibiotic that Targets the Bacillus Anthracis Membrane. ACS Infect. Dis. 2, 207-220. doi:10.1021/ acsinfecdis.5b00115

Mwangi, J., Yin, Y., Wang, G., Yang, M., Li, Y., Zhang, Z., et al. (2019). The Antimicrobial Peptide ZY4 Combats Multidrug-Resistant Pseudomonas aeruginosa and Acinetobacter Baumannii Infection. Proc. Natl. Acad. Sci. U.S.A. 116, 26516-26522. doi:10.1073/pnas.1909585117

Nagy, E., Nagy, G., Power, C. A., Badarau, A., and Szijártó, V. (2017). Anti-bacterial Monoclonal Antibodies. Adv. Exp. Med. Biol. 1053, 119-153. doi:10.1007/9783-319-72077-7_7

Nungester, W. J., and Watrous, R. M. (1934). Accumulation of Bacteriophage in Spleen and Liver Following its Intravenous Inoculation. Exp. Biol. Med. 31, 901-905. doi:10.3181/00379727-31-7367c
O'Neill, J. (2016). Tackling drug-resistant infections globally: Final report and recommendations. Report.

Oechslin, F. (2018). Resistance Development to Bacteriophages Occurring during Bacteriophage Therapy. Viruses 10, 351. doi:10.3390/v10070351

Palmer, J. D., Piattelli, E., Mccormick, B. A., Silby, M. W., Brigham, C. J., and Bucci, V. (2018). Engineered Probiotic for the Inhibition of Salmonella via Tetrathionate-Induced Production of Microcin H47. ACS Infect. Dis. 4, 39-45. doi:10.1021/acsinfecdis.7b00114

Pantůcek, R., Rosypalová, A., Doskar, J., Kailerová, J., Růzicková, V., Borecká, P., et al. (1998). The Polyvalent Staphylococcal Phage Phi 812: its Host-Range Mutants and Related Phages. Virology 246, 241-252. doi:10.1006/viro.1998. 9203

Park, J. Y., Moon, B. Y., Park, J. W., Thornton, J. A., Park, Y. H., and Seo, K. S. (2017). Genetic Engineering of a Temperate Phage-Based Delivery System for CRISPR/Cas9 Antimicrobials against Staphylococcus aureus. Sci. Rep. 7, 44929. doi:10.1038/srep44929

Patel, M., and Kaufman, D. A. (2015). Anti-lipoteichoic Acid Monoclonal Antibody (Pagibaximab) Studies for the Prevention of Staphylococcal Bloodstream Infections in Preterm Infants. Expert Opin. Biol. Ther. 15, 595-600. doi:10.1517/14712598.2015.1019857

Paterson, D. L., Hujer, K. M., Hujer, A. M., Yeiser, B., Bonomo, M. D., Rice, L. B., et al. (2003). Extended-spectrum Beta-Lactamases in Klebsiella pneumoniae Bloodstream Isolates from Seven Countries: Dominance and Widespread Prevalence of SHV- and CTX-M-type Beta-Lactamases. Aac 47, 3554-3560. doi:10.1128/aac.47.11.3554-3560.2003

Patrzykat, A., Friedrich, C. L., Zhang, L., Mendoza, V., and Hancock, R. E. W. (2002). Sublethal Concentrations of Pleurocidin-Derived Antimicrobial Peptides Inhibit Macromolecular Synthesis in Escherichia coli. Aac 46, 605-614. doi:10.1128/aac.46.3.605-614.2002

Peng, M., Tabashsum, Z., Patel, P., Bernhardt, C., and Biswas, D. (2018). Linoleic Acids Overproducing Lactobacillus Casei Limits Growth, Survival, and Virulence of Salmonella Typhimurium and Enterohaemorrhagic Escherichia coli. Front. Microbiol. 9, 2663. doi:10.3389/fmicb.2018.02663

Petrosillo, N., Granata, G., and Cataldo, M. A. (2018). Novel Antimicrobials for the Treatment of Clostridium difficile Infection. Front. Med. 5, 96. doi:10.3389/ fmed.2018.00096

Pursey, E., Sünderhauf, D., Gaze, W. H., Westra, E. R., and Van Houte, S. (2018). CRISPR-cas Antimicrobials: Challenges and Future Prospects. Plos Pathog. 14, e1006990. doi:10.1371/journal.ppat.1006990

Qian, X., Yanagi, K., Kane, A. V., Alden, N., Lei, M., Snydman, D. R., et al. (2020). Ridinilazole, a Narrow Spectrum Antibiotic for Treatment of Clostridioides Difficile Infection, Enhances Preservation of Microbiota-dependent Bile Acids. Am. J. Physiology-Gastrointestinal Liver Physiol. 319, G227-G237. doi:10.1152/ ajpgi.00046.2020

Regeimbal, J. M., Jacobs, A. C., Corey, B. W., Henry, M. S., Thompson, M. G., Pavlicek, R. L., et al. (2016). Personalized Therapeutic Cocktail of Wild Environmental Phages Rescues Mice from Acinetobacter Baumannii Wound Infections. Antimicrob. Agents Chemother. 60, 5806-5816. doi:10.1128/aac. 02877-15

Rodrigues, M., Mcbride, S. W., Hullahalli, K., Palmer, K. L., and Duerkop, B. A. (2019). Conjugative Delivery of CRISPR-Cas9 for the Selective Depletion of Antibiotic-Resistant Enterococci. Antimicrob. Agents Chemother. 63, e01454-19. doi:10.1128/aac.01454-19

Saeidi, N., Wong, C. K., Lo, T. M., Nguyen, H. X., Ling, H., Leong, S. S. J., et al. (2011). Engineering Microbes to Sense and Eradicate Pseudomonas aeruginosa, a Human Pathogen. Mol. Syst. Biol. 7, 521. doi:10.1038/msb.2011.55

Satishkumar, R., and Vertegel, A. A. (2011). Antibody-directed Targeting of Lysostaphin Adsorbed onto Polylactide Nanoparticles Increases its Antimicrobial Activity against S. aureus In Vitro. Nanotechnology 22, 505103. doi:10.1088/0957-4484/22/50/505103

Schooley, R. T., Biswas, B., Gill, J. J., Hernandez-Morales, A., Lancaster, J., Lessor, L., et al. (2017). Development and Use of Personalized Bacteriophage-Based Therapeutic Cocktails to Treat a Patient with a Disseminated Resistant Acinetobacter Baumannii Infection. Antimicrob. Agents Chemother. 61, e00954-17. doi:10.1128/aac.00954-17

Schuch, R., Khan, B. K., Raz, A., Rotolo, J. A., and Wittekind, M. (2017). Bacteriophage Lysin CF-301, a Potent Anti-staphylococcal Biofilm Agent. Antimicrob. Agents Chemother. 61, e02666-16. doi:10.1128/aac.02666-16 
Sears, P., Ichikawa, Y., Ruiz, N., and Gorbach, S. (2013). Advances in the Treatment ofClostridium Difficilewith Fidaxomicin: a Narrow Spectrum Antibiotic. Ann. N.Y. Acad. Sci. 1291, 33-41. doi:10.1111/nyas.12135

Sharma, A., Vaghasiya, K., Ray, E., and Verma, R. K. (2018). Nano-encapsulated HHC10 Host Defense Peptide (HDP) Reduces the Growth of Escherichia coli via Multimodal Mechanisms. Artif. Cell Nanomedicine, Biotechnol. 46, S156-S165. doi:10.1080/21691401.2018.1489823

Sharma, U., Vipra, A., and Channabasappa, S. (2018). Phage-derived Lysins as Potential Agents for Eradicating Biofilms and Persisters. Drug Discov. Today 23, 848-856. doi:10.1016/j.drudis.2018.01.026

Shlezinger, M., Coppenhagen-Glazer, S., Gelman, D., Beyth, N., and Hazan, R. (2019). Eradication of Vancomycin-Resistant Enterococci by Combining Phage and Vancomycin. Viruses 11, 954. doi:10.3390/v11100954

Shokri, R., Salouti, M., and Zanjani, R. S. (2015). Anti Protein A Antibody-Gold Nanorods Conjugate: a Targeting Agent for Selective Killing of Methicillin Resistant Staphylococcus aureus Using Photothermal Therapy Method. J. Microbiol. 53, 116-121. doi:10.1007/s12275-015-4519-4

Smith, P. A., Koehler, M. F. T., Girgis, H. S., Yan, D., Chen, Y., Chen, Y., et al. (2018). Optimized Arylomycins Are a New Class of Gram-Negative Antibiotics. Nature 561, 189-194. doi:10.1038/s41586-018-0483-6

Subramanian, G. M., Cronin, P. W., Poley, G., Weinstein, A., Stoughton, S. M., Zhong, J., et al. (2005). A Phase 1 Study of PAmAb, a Fully Human Monoclonal Antibody against Bacillus Anthracis Protective Antigen, in Healthy Volunteers. Clin. Infect. Dis. 41, 12-20. doi:10.1086/430708

Suez, J., Zmora, N., Segal, E., and Elinav, E. (2019). The Pros, Cons, and Many Unknowns of Probiotics. Nat. Med. 25, 716-729. doi:10.1038/s41591-0190439-x

Sybesma, W., Rohde, C., Bardy, P., Pirnay, J. P., Cooper, I., Caplin, J., et al. (2018). Silk Route to the Acceptance and Re-implementation of Bacteriophage Therapy-Part II. Antibiotics 7, 35. doi:10.5553/cjb/221132662018007003003

Szamosvári, D., Schuhmacher, T., Hauck, C. R., and Böttcher, T. (2019). A Thiochromenone Antibiotic Derived from the Pseudomonas Quinolone Signal Selectively Targets the Gram-Negative Pathogen Moraxella Catarrhalis. Chem. Sci. 10, 6624-6628. doi:10.1039/c9sc01090d

Thomsen, K., Christophersen, L., Bjarnsholt, T., Jensen, P. Ø., Moser, C., and Høiby, N. (2016). Anti- Pseudomonas aeruginosa IgY Antibodies Augment Bacterial Clearance in a Murine Pneumonia Model. J. Cystic Fibrosis 15, 171-178. doi:10.1016/j.jcf.2015.08.002

Torres-Barceló, C., and Hochberg, M. E. (2016). Evolutionary Rationale for Phages as Complements of Antibiotics. Trends Microbiol. 24, 249-256. doi:10.1016/j. tim.2015.12.011

Turner, D., Wand, M. E., Briers, Y., Lavigne, R., Sutton, J. M., and Reynolds, D. M. (2017). Characterisation and Genome Sequence of the Lytic Acinetobacter Baumannii Bacteriophage vB_AbaS_Loki.PLoS One 12, e0172303.doi:10.1371/ journal.pone.0172303

Twort, F. W. (1915). An Investigation on the Nature of Ultra-microscopic Viruses. The Lancet 186, 1241-1243. doi:10.1016/s0140-6736(01)20383-3

Uchiyama, J., Shigehisa, R., Nasukawa, T., Mizukami, K., Takemura-Uchiyama, I., Ujihara, T., et al. (2018). Piperacillin and Ceftazidime Produce the Strongest Synergistic Phage-Antibiotic Effect in Pseudomonas aeruginosa. Arch. Virol. 163, 1941-1948. doi:10.1007/s00705-018-3811-0

Volzing, K., Borrero, J., Sadowsky, M. J., and Kaznessis, Y. N. (2013). Antimicrobial Peptides Targeting Gram-Negative Pathogens, Produced and Delivered by Lactic Acid Bacteria. ACS Synth. Biol. 2, 643-650. doi:10.1021/sb4000367

Walsh, T. R., Weeks, J., Livermore, D. M., and Toleman, M. A. (2011). Dissemination of NDM-1 Positive Bacteria in the New Delhi Environment and its Implications for Human Health: an Environmental Point Prevalence Study. Lancet Infect. Dis. 11, 355-362. doi:10.1016/s1473-3099(11)70059-7

Wang, C., Wang, Y., Zhang, L., Miron, R. J., Liang, J., Shi, M., et al. (2018). Pretreated Macrophage-Membrane-Coated Gold Nanocages for Precise Drug Delivery for Treatment of Bacterial Infections. Adv. Mater. 30, e1804023. doi:10.1002/adma.201804023

Wang, H., La Russa, M., and Qi, L. S. (2016). CRISPR/Cas9 in Genome Editing and beyond. Annu. Rev. Biochem. 85, 227-264. doi:10.1146/annurev-biochem060815-014607

Waters, E. M., Neill, D. R., Kaman, B., Sahota, J. S., Clokie, M. R. J., Winstanley, C., et al. (2017). Phage Therapy Is Highly Effective against Chronic Lung Infections withPseudomonas Aeruginosa. Thorax 72, 666-667. doi:10.1136/thoraxjnl2016-209265

Weems, J. J., Jr., Steinberg, J. P., Filler, S., Baddley, J. W., Corey, G. R., Sampathkumar, P., et al. (2006). Phase II, Randomized, Double-Blind, Multicenter Study Comparing the Safety and Pharmacokinetics of Tefibazumab to Placebo for Treatment of Staphylococcus aureus Bacteremia. Aac 50, 2751-2755. doi:10.1128/aac.00096-06

Wilcox, M. H., Gerding, D. N., Poxton, I. R., Kelly, C., Nathan, R., Birch, T., et al. (2017). Bezlotoxumab for Prevention of RecurrentClostridium difficileInfection. N. Engl. J. Med. 376, 305-317. doi:10.1056/nejmoa1602615

Williams, N. T. (2010). Probiotics. Am. J. Health Syst. Pharm. 67, 449-458. doi:10. 2146/ajhp090168

Winter, S. E., Thiennimitr, P., Winter, M. G., Butler, B. P., Huseby, D. L., Crawford, R. W., et al. (2010). Gut Inflammation Provides a Respiratory Electron Acceptor for Salmonella. Nature 467, 426-429. doi:10.1038/nature09415

Yang, S., Han, X., Yang, Y., Qiao, H., Yu, Z., Liu, Y., et al. (2018). Bacteria-targeting Nanoparticles with Microenvironment-Responsive Antibiotic Release to Eliminate Intracellular Staphylococcus aureus and Associated Infection. ACS Appl. Mater. Inter. 10, 14299-14311. doi:10.1021/acsami.7b15678

Ying, M., Zhuang, J., Wei, X., Zhang, X., Zhang, Y., Jiang, Y., et al. (2018). Remoteloaded Platelet Vesicles for Disease-Targeted Delivery of Therapeutics. Adv. Funct. Mater. 28, 1801032. doi:10.1002/adfm.201801032

Yu, X.-Q., Robbie, G. J., Wu, Y., Esser, M. T., Jensen, K., Schwartz, H. I., et al. (2017). Safety, Tolerability, and Pharmacokinetics of MEDI4893, an Investigational, Extended-Half-Life, Anti-Staphylococcus aureus AlphaToxin Human Monoclonal Antibody, in Healthy Adults, in Healthy Adults. Antimicrob. Agents Chemother. 61, e01020-16. doi:10.1128/aac.01020-16

Zimmer, M., Vukov, N., Scherer, S., and Loessner, M. J. (2002). The Murein Hydrolase of the Bacteriophage $\varphi 3626$ Dual Lysis System Is Active against All Tested Clostridium perfringens Strains. Aem 68, 5311-5317. doi:10.1128/aem. 68.11.5311-5317.2002

Zipperer, A., Konnerth, M. C., Laux, C., Berscheid, A., Janek, D., Weidenmaier, C., et al. (2016). Human Commensals Producing a Novel Antibiotic Impair Pathogen Colonization. Nature 535, 511-516. doi:10.1038/nature18634

Conflict of Interest: The authors declare that the research was conducted in the absence of any commercial or financial relationships that could be construed as a potential conflict of interest.

Copyright (c) 2021 Yang, Fang, Lv, Wang and Liu. This is an open-access article distributed under the terms of the Creative Commons Attribution License (CC BY). The use, distribution or reproduction in other forums is permitted, provided the original author(s) and the copyright owner(s) are credited and that the original publication in this journal is cited, in accordance with accepted academic practice. No use, distribution or reproduction is permitted which does not comply with these terms. 